\title{
Role of TRPM8 Channels in Altered Cold Sensitivity of Corneal Primary Sensory Neurons Induced by Axonal Damage
}

\author{
Ricardo Piña, ${ }^{1,2}$ Gonzalo Ugarte, ${ }^{1}$ Matías Campos, ${ }^{1}$ Almudena Íñigo-Portugués, ${ }^{3}$ Erick Olivares, ${ }^{4}$ Patricio Orio, ${ }^{4}$ \\ (C) Carlos Belmonte, ${ }^{3}$ ๑Juan Bacigalupo, ${ }^{2}$ and ${ }^{\circledR}$ Rodolfo Madrid ${ }^{1}$ \\ ${ }^{1}$ Departamento de Biología, Facultad de Química y Biología, and Millennium Nucleus of Ion Channels-Associated Diseases (MiNICAD), Universidad de \\ Santiago de Chile, 9160000 Santiago, Chile, ${ }^{2}$ Departamento de Biología, Facultad de Ciencias, Universidad de Chile, 7750000 Ñunoa, Santiago, Chile, \\ ${ }^{3}$ Instituto de Neurociencias, UMH-CSIC, 03550 San Juan de Alicante, Spain, and ${ }^{4}$ Centro Interdisciplinario de Neurociencia de Valparaíso (CINV) and \\ Instituto de Neurociencia, Facultad de Ciencias, Universidad de Valparaíso, 2340000 Valparaíso, Chile
}

The cornea is extensively innervated by trigeminal ganglion cold thermoreceptor neurons expressing TRPM8 (transient receptor potential cation channel subfamily M member 8). These neurons respond to cooling, hyperosmolarity and wetness of the corneal surface. Surgical injury of corneal nerve fibers alters tear production and often causes dry eye sensation. The contribution of TRPM8-expressing corneal cold-sensitive neurons (CCSNs) to these symptoms is unclear. Using extracellular recording of CCSNs nerve terminals combined with in vivo confocal tracking of reinnervation, $\mathrm{Ca}^{2+}$ imaging and patch-clamp recordings of fluorescent retrogradely labeled corneal neurons in culture, we analyzed the functional modifications of CCSNs induced by peripheral axonal damage in male mice. After injury, the percentage of CCSNs, the cold- and menthol-evoked intracellular $\left[\mathrm{Ca}^{2+}\right]$ rises and the TRPM8 current density in CCSNs were larger than in sham animals, with no differences in the brake $\mathrm{K}^{+}$current $I_{\mathrm{KD}}$. Active and passive membrane properties of CCSNs from both groups were alike and corresponded mainly to those of canonical low- and high-threshold cold thermoreceptor neurons. Ongoing firing activity and menthol sensitivity were higher in CCSN terminals of injured mice, an observation accounted for by mathematical modeling. These functional changes developed in parallel with a partial reinnervation of the cornea by TRPM8(+) fibers and with an increase in basal tearing in injured animals compared with sham mice. Our results unveil key TRPM8-dependent functional changes in CCSNs in response to injury, suggesting that increased tearing rate and ocular dryness sensation derived from deep surgical ablation of corneal nerves are due to enhanced functional expression of TRPM8 channels in these injured trigeminal primary sensory neurons.

Key words: cold hypersensitivity; cold thermoreceptor neurons; cornea; dry eye sensation; nerve injury; tearing rate

Significance Statement

We unveil a key role of TRPM8 channels in the sensory and autonomic disturbances associated with surgical damage of eye surface nerves. We studied the damage-induced functional alterations of corneal cold-sensitive neurons using confocal tracking of reinnervation, extracellular corneal nerve terminal recordings, tearing measurements in vivo, $\mathrm{Ca}^{2+}$ imaging and patch-clamp recordings of cultured corneal neurons, and mathematical modeling. Corneal nerve ablation upregulates TRPM8 mainly in canonical cold thermoreceptors, enhancing their cold and menthol sensitivity, inducing a rise in the ongoing firing activity of TRPM8(+) nerve endings and an increase in basal tearing. Our results suggest that unpleasant dryness sensations, together with augmented tearing rate after corneal nerve injury, are largely due to upregulation of TRPM8 in cold thermoreceptor neurons.

\section{Introduction}

The cornea of the eye is equipped with the largest sensory nerve supply of all body tissues (Marfurt et al., 2010). This abundant innervation provides sensory information to the brain mediating cognitive, behavioral and autonomic responses to potentially injurious

Received March 21, 2019; revised Aug. 7, 2019; accepted Aug. 12, 2019.

Author contributions: R.P., G.U., M.C., A.I-P., E.O.,P.O., and R.M. performed research; R.P., G.U., M.C., A.Í-P., E.0.,

P.O., and R.M. analyzed data; R.M. wrote the first draft of the paper; P.O., C.B., J.B., and R.M. edited the paper; C.B.,

J.B., and R.M. designed research; R.M. wrote the paper. stimuli, and contributes to the maintenance of corneal homeostasis through trophic support of corneal cells and regulation of ocular surface wetness and blinking rate (Belmonte et al., 2004, 2017).

Primary sensory neurons innervating the cornea are located in the ophthalmic division of the trigeminal ganglion. Functionally, 
most corneal sensory axons are mechano- and polymodal nociceptors that respond to noxious mechanical, thermal and chemical stimuli (Belmonte et al., 2017; González-González et al., 2017). A remaining fraction of corneal fibers $(\sim 12 \%)$ are cold thermoreceptors, primarily activated by moderate cooling of the ocular surface (Parra et al., 2010; Belmonte et al., 2017; GonzálezGonzález et al., 2017). As occurs with peripheral cold thermoreceptor neurons of other somatosensory territories, this cold detection capacity is strongly dependent on the TRPM8 (transient receptor potential cation channel subfamily $\mathrm{M}$ member 8) expression, a multimodal cationic ion channel activated by low temperatures, cooling compounds such as menthol, voltage and discrete osmolality rises (McKemy et al., 2002; Peier et al., 2002; Brauchi et al., 2004; Voets et al., 2004; Parra et al., 2014; Quallo et al., 2015); for reviews, see (Almaraz et al., 2014; Madrid and Pertusa, 2014; Vriens et al., 2014; Carrasquel-Ursulaez et al., 2015; González et al., 2015).

The peculiar functional roles of corneal cold thermoreceptors are still under scrutiny. Their peripheral endings not only detect small temperature reductions as do canonical cold thermoreceptor neurons of the skin (Hensel and Zotterman, 1951; Iggo, 1969), but they also function as accurate dryness detectors, maintaining ocular surface wetness by adjusting the basal tearing rate and spontaneous blinking frequency (Hirata and Meng, 2010; Parra et al., 2010; Quallo et al., 2015). Evaporation of the tear film causes small temperature reductions and increases in tear osmolality that are detected and coded by corneal cold-sensitive fibers named high-background low-threshold cold thermoreceptors (HB-LTCs). These neurons present a background firing rate at the normal temperature of the cornea $\left(\sim 34^{\circ} \mathrm{C}\right)$, which markedly increases with small temperature decreases $\left(<1^{\circ} \mathrm{C}\right)$ (Brock et al., 1998, 2001; Carr et al., 2003; Parra et al., 2010). The remainder of the cold-sensitive neurons, named low-background high-threshold cold thermoreceptors (LB-HTCs), exhibit a low background impulse activity at $34^{\circ} \mathrm{C}$ and require large temperature reductions to increase their firing rate. It has been proposed that HB-LTCs tonically modulate basal tearing and blinking rates, whereas LBHTCs are mainly implicated in evoking sensations associated to corneal dryness (Parra et al., 2010; Hirata et al., 2012; Quallo et al., 2015; Bech et al., 2018).

Peripheral axons and nerve terminals of corneal sensory neurons are easily exposed to noxious stimuli, infections and inflammatory processes of the anterior segment of the eye, and their activation evokes acute intense pain (Belmonte et al., 2015). Eye surface nerves are variably injured by surgical procedures such as photorefractive or cataract surgery, tear film pathologies such as dry eye disease (DED), or by wearing contact lenses (Belmonte et al., 2004, 2015, 2017; Belmonte and Gallar, 2011; Rosenthal and Borsook, 2012; Stapleton et al., 2013; Chao et al., 2014). These diverse conditions cause nerve damage that varies in severity, extension and evolution, thus explaining the heterogeneity of evoked discomfort, pain symptoms and altered reflex autonomic responses. Recent studies suggest a significant contribution of

Viana and Cruz Morenilla for kindly providing the TRPM8 ${ }^{\text {BAC }}$-EYFP mice; Dr. María Pertusa for valuable input and continued support throughout this work; Richard Pino for excellent technical assistance; and Yolanda Aránguiz for contribution to animal care. MiNICAD is a Millennium Nucleus supported by the Millennium Science Initiative of the Ministry of Economy, Development and Tourism (Chile). The CINV is a Millennium Science Institute funded by the Ministry of Economy, Development and Tourism (Chile). R.M. thanks Pfizer (WI177114) for providing PBMCs and VRIDEI-USACH for support to G.U. and R.P.

The authors declare no competing financial interests.

Correspondence should be addressed to Rodolfo Madrid at rodolfo.madrid@usach.cl.

https://doi.org/10.1523/JNEUROSCI.0654-19.2019

Copyright $\odot 2019$ the authors corneal cold thermoreceptors injury to dysesthesias and tearing disturbances that accompany photorefractive surgery and eye dryness, two common causes of ocular surface discomfort and pain (Acosta et al., 2013; Chao et al., 2014; Galor et al., 2015; Kovács et al., 2016a,b; Belmonte et al., 2017).

Here, we explored the changes of thermal and chemical sensitivity, excitability and TRPM8 functional expression in mice corneal cold thermoreceptors following controlled surgical damage of peripheral axons to determine their contribution to discomfort, pain and autonomic disturbances in ocular surface disorders involving damage to corneal nerves.

\section{Materials and Methods}

Animals. This study was performed using young male adults [postnatal day 21 (P21) to P40] BALB/c and TRPM8 ${ }^{\text {BAC }}$-EYFP transgenic mice (Morenilla-Palao et al., 2014). Animals were housed in a $12 \mathrm{~h}$ light/dark cycle, with food and water available ad libitum, and were euthanized with $\mathrm{CO}_{2}$. All experiments were conducted according to the bioethical guidelines of the Comisión Nacional de Investigación Científica y Tecnológica de Chile (CONICYT) and the Bioethical Committee of the University of Santiago de Chile (Protocol Reference Number 283). We followed the protocol approved and supervised by the Ethics Committee of the Universidad Miguel Hernández de Elche, in accordance with the Association for Research in Vision and Ophthalmology (ARVO) Statement for the Use of Animals in Ophthalmic and Vision Research, the European Union Directive (2010/63/EU) and the Spanish regulations regarding the protection of animals used for research (RD 53/2013).

Model of surgical injury of corneal sensory axons in mice. We used controlled cutting of stromal nerve fibers as a model of corneal nerve damage. In brief, surgery was performed on the right eye of each animal, anesthetized with ketamine $(80 \mathrm{mg} / \mathrm{kg})$ and xylazine $(10 \mathrm{mg} / \mathrm{kg})$. The eye was immobilized by sustained pressure using a plastic O-ring. A partial incision $\left(\sim 15^{\circ}\right)$ tangential to the corneal surface was made using a 15 degree, straight regular ophthalmic knife (Accutome; MST Basic) to create a corneal pocket. This pocket was then expanded until $\sim 330^{\circ}$, forming a surface flap of $2 \mathrm{~mm}$ in diameter attached to the cornea by a $\sim 30^{\circ}$ hinge (see Fig. 1A). For sham controls, animals were also anesthetized and the right eye was immobilized, but not operated. Animals received analgesic treatment (buprenorphine $0.02 \mathrm{mg} / \mathrm{kg}$ s.c. repeated every $12 \mathrm{~h}$ ) during the first $3 \mathrm{~d}$ after surgery. All animals used in this study presented a complete recovery of the corneal wound to naked eye after $7 \mathrm{~d}$.

Retrograde labeling of trigeminal corneal neurons. Labeling of corneal neurons with FM1-43 fluorescent dye (T35356; Thermo Fisher Scientific) was performed on anesthetized mice. The treated eye was immobilized and a $2 \mathrm{~mm}^{2}$ piece of absorbable filter paper soaked in 1-heptanol $98 \%$ was applied on the cornea ( $1 \mathrm{~s}$ ) for gentle elimination of the corneal epithelium, and to facilitate the access of the fluorescent tracer to the nerve endings. Immediately afterward, a drop of $0.5 \mu \mathrm{l}$ of $5 \mathrm{~mm}$ FM1-43 in $0.9 \%$ saline buffer was applied every $15 \mathrm{~min}$ for one hour. During the procedure, the animal was maintained under deep anesthesia, with the eye open. Finally, the eyes were quickly washed with an equal number of saline solution drops. After FM1-43 application, mice were left with food and water ad libitum for four days before the experiments, allowing transportation of the fluorescent marker to the soma of trigeminal corneal neurons.

Tear flow and corneal temperature measurements. Phenol red-treated threads (Zone Quick; Menicon) were used to measure tearing flow as described previously (Parra et al., 2010). In anesthetized animals, the thread was gently placed on the internal angle of the eye, kept in place for $2 \mathrm{~min}$, and then removed and quantified. The length of the stained portion was measured under a stereomicroscope with a calibrated scale. Tear flow was measured at days 0 (immediately before injury), 17 (retrograde labeling day) and 21 (culture day; see below) following injury, both in sham and injured mice. For the specific blockade of TRPM8 at corneal nerve endings, a drop of 1-phenylethyl-4(benzyloxy)-3-ethoxy benzyl (2 aminoethyl) carbamate (PBMC) solution ( $20 \mu \mathrm{M}$ in saline) was applied to the corneal surface during $40 \mathrm{~min}$ in anesthetized mice, and then 
removed before placing the thread to measure tearing flow. Tear production was undistinguishable before and after $40 \mathrm{~min}$ when a drop of saline solution was used instead PBMC as control, in both groups of animals (data not shown). In these experiments, corneal temperature was monitored using a BAT-12 microprobe thermometer (Physitemp Instruments) supplemented with an IT-18 T-thermocouple. Corneal temperature was identical in both groups of animals in all tearing tests.

Cell culture. Pairs of sham and injured animals were euthanized by $\mathrm{CO}_{2}$ inhalation. After decapitation, right (ipsilateral) trigeminal ganglia (TG) were removed and incubated in an enzymatic mixture in INC-mix solution (in mM: $155 \mathrm{NaCl}, 1.5 \mathrm{~K}_{2} \mathrm{HPO}_{4}, 10$ HEPES, 5 glucose, $\mathrm{pH}: 7.4$ ) containing collagenase type XI ( $650 \mathrm{UI} / \mathrm{mL}$; C7657; Sigma-Aldrich) and dispase ( $5 \mathrm{UI} / \mathrm{mL} ; 17105-041$ Invitrogen) for $40 \mathrm{~min}$ at $37^{\circ} \mathrm{C}$ in $5 \% \mathrm{CO}_{2}$. The ganglia were then mechanically dissociated with polished Pasteur pipettes and the neurons were plated on poly-L-lysine-coated $6 \mathrm{~mm} \# 0$ glass coverslips (Menzel-Gläser), maintained in MEM (Earle's salts, 11095080; Invitrogen) supplemented with MEM-vit (11120052; Invitrogen), 10\% FBS (SH30910.03; Hyclone), $200 \mu \mathrm{g} / \mathrm{mL}$ streptomycin, 125 $\mu \mathrm{g} / \mathrm{mL}$ penicillin (15140-122; Invitrogen), and used within 6 to $12 \mathrm{~h}$ for $\left[\mathrm{Ca}^{2+}\right]_{\mathrm{i}}$ imaging and patch-clamp recordings. Pairs of sham and injured mice were tested simultaneously. $\mathrm{Ca}^{2+}$ imaging and patch-clamp experiments were performed for both conditions, injured and sham, always $21 \mathrm{~d}$ after surgery.

$\mathrm{Ca}^{2+}$ imaging. For ratiometric $\mathrm{Ca}^{2+}$ imaging experiments, trigeminal neurons were incubated in $5 \mu \mathrm{M}$ Fura-2 AM (F1221; Invitrogen) in standard extracellular solution supplemented with $0.02 \%$ pluronic acid (P6867; Invitrogen) for $50 \mathrm{~min}$ at $37^{\circ} \mathrm{C}$, in darkness. Fluorescence measurements were obtained using an inverted Nikon Ti microscope equipped with a Super Plan Fluor ELWD 20XC objective numerical aperture 0.45 and a 12-bit cooled ORCA C8484-03G02 CCD camera (Hamamatsu). Fura-2 was excited at 340 and $380 \mathrm{~nm}$ with a Polychrome $\mathrm{V}$ monochromator (Till Photonics), with exposure times no longer than $40 \mathrm{~ms}$; the emitted fluorescence was filtered with a $510 \mathrm{~nm}$ long-pass filter. Calibrated ratios $(0.5 \mathrm{~Hz})$ were displayed online with HCImage v2 software (Hamamatsu). Bath temperature (see details below) was sampled simultaneously using a BAT-12 microprobe thermometer (Physitemp Instruments) supplemented with an IT-18 T-thermocouple, using Clampex 10 software (Molecular Devices). The signal was digitized with an Axon Digidata 1440A AD converter (Molecular Devices).

Threshold temperature values for the rise in $\left[\mathrm{Ca}^{2+}\right]_{i}$ were estimated as in (Madrid et al., 2009). For this, temperature was linearly interpolated at the midpoint between the baseline and the first point at which $\left[\mathrm{Ca}^{2+}\right]_{\mathrm{i}}$ elevation deviates by at least four times the SD of the baseline. The increase in intracellular $\left[\mathrm{Ca}^{2+}\right]$ in cultured cold sensitive neurons is due to $\mathrm{Ca}^{2+}$ entry through voltage-gated $\mathrm{Ca}^{2+}$ channels, which are activated during action potential firing. A very tight correlation between threshold temperature detected in the $\left[\mathrm{Ca}^{2+}\right]_{\mathrm{i}}$ signal and the threshold of action potential firing recorded in cell-attached mode (Viana et al., 2002; Madrid et al., 2009; González et al., 2015) allows the use of this non-invasive method to determine the thermal threshold of several cold-sensitive neurons simultaneously. In the quantification of the percentage of CCSNs in both sets of mice, an extracellular solution containing elevated $\mathrm{K}^{+}(30 \mathrm{~mm} \mathrm{KCl})$ was perfused at the end of the protocol to determine the viability of the neurons in the entire field; only neurons showing a $\left[\mathrm{Ca}^{2+}\right]_{\mathrm{i}}$ increase in response to high extracellular $\mathrm{K}^{+}$were included in the analysis.

Electrophysiology. In patch-clamp experiments, current and voltage signals were recorded using an Axopatch 200B amplifier (Molecular Devices), and temperature was monitored simultaneously in either wholecell voltage- or current-clamp recordings. Stimuli delivery and data acquisition were performed using pClamp 10 software (Molecular Devices). The extracellular standard solution contained the following (in mM): $140 \mathrm{NaCl}, 3 \mathrm{KCl}, 1.3 \mathrm{MgCl}_{2}, 2.4 \mathrm{CaCl}_{2}, 10$ HEPES, 10 glucose, 298 $\mathrm{mOsm} / \mathrm{kg}, \mathrm{pH} 7.4$, adjusted with $\mathrm{NaOH}$. Standard patch pipettes $(4-5$ $\mathrm{M} \Omega$ resistance) were made using GC150F-7.5 glass capillaries (Harvard Apparatus) and filled with intracellular solution containing the following (in mM): $105 \mathrm{~K}$-gluconate, $35 \mathrm{KCl}, 8.8 \mathrm{NaCl}, 10$ HEPES, 0.5 EGTA, 4 MgATP, $0.4 \mathrm{NaGTP}, 300 \mathrm{mOsm} / \mathrm{kg}$, pH 7.4, adjusted with KOH. Before electrophysiological recordings in CCSNs, the temperature threshold in response to cold stimuli was determined using $\mathrm{Ca}^{2+}$ imaging.

Temperature stimulation. Coverslips with plated cells were placed in a microchamber and continuously perfused $(\sim 1 \mathrm{~mL} / \mathrm{min})$ with solutions at $\sim 34^{\circ} \mathrm{C}$. The bath temperature was adjusted with a water-cooled computer-controlled Peltier device, with the outlet located on the imaging field and controlled by a feedback device. In extracellular recordings of CCSNs in vitro, the temperature of the bath was maintained using a CS-1 temperature controller (Cool Solutions Research Devices; see below).

In all cases, cold sensitivity was investigated using 30-40 s ramp-like temperature drops to $20^{\circ} \mathrm{C}$ from a basal temperature of $34^{\circ} \mathrm{C}$, either in control solution or in the presence of different compounds applied using the same perfusion system.

Experimental protocols. The first step in the protocol of $\mathrm{Ca}^{2+}$ imaging experiments was to determine the temperature response threshold to cold measuring the elevation in $\left[\mathrm{Ca}^{2+}\right]_{\mathrm{i}}$. The contribution of the brake potassium current $I_{\mathrm{KD}}$ to the thermal threshold of CCSNs was assessed by using $100 \mu \mathrm{M} 4$-aminopyridine (4-AP) as a blocker. To determine the neurochemical profile of CCSNs, stimuli of $100 \mu \mathrm{M}$ menthol and $100 \mu \mathrm{M}$ menthol plus cold (TRPM8 activators), $100 \mu \mathrm{M}$ allyl isothiocyanate (AITC, TRPA1 activator) and $200 \mathrm{~nm}$ capsaicin (TRPV1 activator) were also used to explore the functional expression of these thermo-TRP channels. The ability to respond to these stimuli was correlated with the thermal threshold and the active and passive membrane properties of the neurons, to determine whether these cells corresponded functionally to canonical low- or high-threshold cold thermoreceptors, or to nociceptors (González et al., 2017b).

For patch-clamp experiments, trigeminal neurons were recorded under current- or voltage-clamp, after determining the temperature threshold by $\mathrm{Ca}^{2+}$ imaging as in (Madrid et al., 2006, 2009). In current-clamp mode, the membrane potential was brought to $-60 \mathrm{mV}$ by current injection, and a series of hyperpolarizing and depolarizing $500 \mathrm{~ms}$ current steps $(\Delta i=10-100 \mathrm{pA}$, depending on input resistance) were delivered at a rate of $0.1 \mathrm{~Hz}$. This protocol allowed us to determine input resistance, rheobase current, spike duration, inward rectification index, and firing pattern. Under voltage-clamp, membrane potential was held at $-50 \mathrm{mV}$, and a $500 \mathrm{~ms}$ hyperpolarizing pulse to $-120 \mathrm{mV}$ was used to remove the inactivation of $I_{\mathrm{KD}}$ (Viana et al., 2002; Madrid et al., 2009) and to estimate the hyperpolarization-activated current $I_{\mathrm{h}}$ (Orio et al., 2009, 2012). The slowly inactivating outward current, measured $1 \mathrm{~s}$ after it returned to $-40 \mathrm{mV}$, corresponds to $I_{\mathrm{KD}}$ (Madrid et al., 2009; González et al., 2017b).

Following this, the membrane potential was held at $-50 \mathrm{mV}$ and the temperature was cooled from $\sim 34^{\circ} \mathrm{C}$ to $\sim 20^{\circ} \mathrm{C}$ to measure the TRPM8dependent cold-sensitive current $\left(I_{\text {cold }}\right)$. The difference between the currents at both temperatures was considered as $I_{\text {cold }}$, and the maximal TRPM8-dependent current was taken as the inward current potentiated by $100 \mu \mathrm{M}$ menthol at $20^{\circ} \mathrm{C}\left(I_{\text {cold }+ \text { menthol }}\right.$; Madrid et al., 2009; González et al., 2017b).

Extracellular recordings of CCSNs. Extracellular recording of nerve terminal impulse (NTI) activity in vitro was performed as described previously (Parra et al., 2010). In brief, eyes were carefully removed from the euthanized animals and placed in a $25 \mathrm{~mL}$ glass containing oxygenated extracellular solution. Excised eyes were then placed in the recording chamber, and the optic nerve and associated tissues were drawn into a suction tube at the bottom of the chamber and continuously perfused ( 1 $\mathrm{mL} / \mathrm{min}$ ) with physiological saline solution of the following composition (in mM): $128 \mathrm{NaCl}, 5 \mathrm{KCl}, 1 \mathrm{NaH}_{2} \mathrm{PO}_{4}, 26 \mathrm{NaHCO}_{3}, 2.4 \mathrm{CaCl}_{2}, 1.3$ $\mathrm{MgCl}_{2}, 10$ glucose, $\mathrm{pH} 7.4$, gassed with carbogen $\left(95 \% \mathrm{O}_{2}, 5 \% \mathrm{CO}_{2}\right)$. The basal temperature of the bath solution was kept at $\sim 34^{\circ} \mathrm{C}$, and was modified using a CS-1 temperature controller (Cool Solutions Research Devices) controlled by a computer, and the outlet was located close to the surface of the eye. A glass pipette (tip diameter: $\sim 50$ to $100 \mu \mathrm{m}$ ) for recording extracellular NTI activity, filled with physiological saline, was positioned onto the corneal epithelium surface and slight suction was applied. Signals were amplified with an 1800 AC amplifier (AM Systems), and the data were acquired and analyzed using an Axon 1332A Digidata $\mathrm{AD}$ converter (Molecular Devices) coupled to a computer running pClamp 9 software (Molecular Devices). Further analysis was performed 
using Spike2 8.0 software (Cambridge Electronic Design). Only nerve impulses that were readily distinguished from noise $(\sim 10 \mu \mathrm{V}$ peak-topeak when low-pass filtered at $5 \mathrm{kHz}$ ) and with similar shape and amplitude were studied.

Cold thermoreceptor nerve endings were identified by their typical spontaneous, often regular, low-frequency impulse activity at $34^{\circ} \mathrm{C}$, which increased during temperature reductions and were transiently silenced by rewarming. Ongoing NTI activity (spontaneous activity) at $34^{\circ} \mathrm{C}$ was recorded for at least $3 \mathrm{~min}$ before cooling. Basal mean ongoing activity (in impulses per second) was calculated during the $30 \mathrm{~s}$ preceding the onset of a $\sim 30 \mathrm{~s}$ ramp-like temperature drop to $20^{\circ} \mathrm{C}$ at a rate of $\sim 0.7^{\circ} \mathrm{C} / \mathrm{s}$. This protocol was repeated during exposure to menthol or PBMC.

In vivo corneal nerve tracking. To study the reinnervation process of nerve fibers at the corneal tissue, control and injured TRPM $8{ }^{\text {BAC }}$-EYFP mice (at 3, 10, 17 and $21 \mathrm{~d}$ after surgery) were used, in which only TRPM8-expressing cold thermoreceptor neurons and their projections displayed green fluorescence. Mice were anesthetized with an intraperitoneal injection of xylazine $(16 \mathrm{mg} / \mathrm{kg})$ followed by inhalation of isoflurane $(1.5 \%)$, and placed in a SGM-4 head holder (Narishige) on the in vivo stage for mouse (Luigs \& Neumann) of a confocal laser scanning Leica SP5II microscope. The cornea was positioned perpendicularly to the objective (HCX PL FLUOTAR CS $5 \times / 0.15$ dry for large field of view) for the visualization of corneal cold-sensitive nerves and imaged on the animal at different time points after radial surgical nerve injury. The total length of regenerated corneal sensory nerves was measured using ImageJ, both in the injured and the noninjured area.

Mathematical model. To corroborate the correlation between firing frequency and TRPM8 functional expression level, we used the model of CCSNs including TRPM8 described previously (Olivares and Orio, 2015; Olivares et al., 2015). The equation for the membrane potential is as follows:

$$
C_{m} \frac{d V}{d t}=-I_{s d}-I_{s r}-I_{d}-I_{r}-I_{M 8}-I_{l}+I_{w n}
$$

where $C_{\mathrm{m}}$ is the membrane capacitance; $I_{\mathrm{sd}}$ and $I_{\mathrm{sr}}$ are, respectively, the slow depolarizing and repolarizing currents that create the intrinsic oscillation of membrane potential; $I_{\mathrm{d}}$ and $I_{\mathrm{r}}$ are Hodgkin and Huxley-type depolarizing and repolarizing currents for action potential firing, respectively; $I_{\mathrm{M} 8}$ is the TRPM8-dependent cold-activated current; $I_{1}$ is an ohmic leakage current; and $I_{\mathrm{wn}}$ is a noise term. Ionic currents are given by the following:

$$
I_{i}=g_{i} a_{i}\left(V-E_{i}\right) \quad(i=s d, s r, d, r, M 8, l)
$$

where $g_{\mathrm{i}}$ represents the maximum conductance density of the current $i$ given by the level of channel expression, $E_{\mathrm{i}}$ is the reversal potential of the current, and $a_{\mathrm{i}}$ is the activation variable or open channel probability usually voltage-dependent except for $a_{\mathrm{i}}=1$ (for the rest of the equations and details, see Olivares and Orio, 2015; Olivares et al., 2015). The invariable $I_{\mathrm{KD}}$ current is contained in the rest of the parameters considered in the model, and therefore it is invariant in all simulations.

As in our previous work (Olivares et al., 2015), we used different sets of parameters that give different types of dynamic responses. The sets used in this study are listed in Table 2 and the common parameters are as follows:

$$
\begin{aligned}
& E_{l}=-70, E_{d}=E_{s d}=50, E_{r}=E_{s r}=-90, E_{M 8}=0(\mathrm{mV}) ; \\
& \tau_{s d}=10, \tau_{s r}=24, \tau_{r}=1.5(\mathrm{~ms}) ; \\
& s_{s d}=0.1, s_{d}=s_{r}=0.25\left(\mathrm{~m}^{-1}\right) ; \\
& V_{s d}^{h}=-40, V_{d}^{h}=V_{r}^{h}=-25(\mathrm{mV}) ; \\
& \eta=0.012\left(\mathrm{~cm}^{2} / \mu \mathrm{A}\right) ; \kappa=0.17 ; \\
& z_{M 8}=0.65\left(\mathrm{mV}^{-1}\right) ; \Delta E=9000(\mathrm{~J}) ; K_{C a, M 8}=0.5(\mu M) ; \\
& d=1(\mu \mathrm{m}) ; D=0.5\left(\mu \mathrm{A} / \mathrm{cm}^{2}\right) ; \tau_{w n}=1(\mathrm{~ms}) .
\end{aligned}
$$

To simulate the effect of menthol, we introduced a $-30 \mathrm{mV}$ shift into the $V_{1 / 2}$ of TRPM8 channel activation. Because this shift is then compensated by the $\mathrm{Ca}^{2+}$-dependent negative feedback introduced in the model, the effective $V_{1 / 2}$ displacement obtained with this procedure was, after stabilization, between -7 and $-10 \mathrm{mV}$ (depending on the parameters), compatible with the effect of $10 \mu \mathrm{M}$ menthol.

The model was implemented in the Neuron simulation environment (RRID:SCR_005393) controlled with Python scripts (RRID: SCR_008394; Hines and Carnevale, 1997; Hines et al., 2009). Analysis of the simulations was performed in Python with the libraries Numpy (RRID:SCR_008633), Scipy (RRID:SCR_008058) and Matplotlib (RRID:SCR_008624).

Statistical analysis. Data are expressed as the mean \pm SEM except where indicated. Differences were considered significant when ${ }^{\star} p<0.05$, ${ }^{* *} p<0.01$ and ${ }^{* * *} p<0.001$ in Student's $t$ test and one-way ANOVA for parametric data, and Fisher's $(F)$ exact test used to compare populations. For unpaired $t$ test, Welch's correction was applied in the case of unequal variances. Holm-Sidak method for multiple comparisons was used as a post hoc test after one-way ANOVA. Except where indicated, all exact $p$-values, statistical tests, and sample sizes are as reported in the figure legends.

Reagents and drugs. L-menthol (menthol, 266523), 4-aminopyridine (4-AP, A78403), allyl isothiocyanate (AITC, 377430), and capsaicin (M2028) were from Sigma-Aldrich. PBMC was kindly provided by Pfizer through its Compound Transfer Program (WI177114 to R.M.).

\section{Results}

\section{In vivo confocal tracking of corneal reinnervation}

Figure $1 A$ shows a scheme of the lesion type used in this study to injure corneal nerve fibers. In Figure $1, B-E$, we show an example of the reinnervation of the cornea by TRPM8 $(+)$ axons followed in vivo with confocal tracking in a TRPM $8{ }^{\mathrm{BAC}}$-EYFP mouse, at different times after creating a deep central corneal wound. At day 3, the TRPM8 $(+)$ innervation of the wounded area was virtually absent; most of the nerve trunks seen in the intact cornea appeared to be interrupted at the wound border, although a few of them (asterisks) had already initiated regeneration and started to penetrate the damaged region (Fig. $1 C, F, G$ ). At day 10 after injury, these regenerating nerve filaments had grown markedly, whereas other nerves started to invade the injured area, thus gradually increasing innervation (see quantification in Fig. $1 F, G$ ). At days 17 and 21 (Fig. $1 D, E$ ), the growth of regenerating fibers in the wounded area was stabilized, although they were still incomplete, and innervation density was lower than before the injury [Fig. $1 F, G$; in $F$, one-way $\operatorname{ANOVA}\left(F_{(4,10)}=5.878,{ }^{*} p=\right.$ 0.0110 ) followed by Holm-Sidak method (preinjury vs $3 \mathrm{~d}, t_{(14)}$ $=4.847,{ }^{* *} p=0.0038$; preinjury vs $10 \mathrm{~d}, t_{(14)}=2.435,{ }^{\star} p=$ $0.0350)$; in $G$, one-way $\operatorname{ANOVA}\left(F_{(4,10)}=38.727,{ }^{* * *} p<0.0010\right)$ followed by Holm-Sidak method (preinjury vs $3 \mathrm{~d}, t_{(14)}=11.857$, ${ }^{*} p=0.0038$; preinjury vs $10 \mathrm{~d}, t_{(14)}=8.960,{ }^{* *} p=0.0029$; preinjury vs $17 \mathrm{~d}, t_{(14)}=8.014,{ }^{* *} p=0.0020$; preinjury vs $21 \mathrm{~d}$, $\left.\left.t_{(14)}=6.747,{ }^{* \star} p=0.0010\right)\right]$. Figure $1, F-H$, offers a quantitative estimation of the regeneration process obtained by measuring the total length of all the fluorescent axons present in the intact peripheral cornea and the wounded area at different time points after injury, showing that around $45 \%$ of the total length value had recovered by day 21 . At the peripheral region surrounding the injured area, the density of nerve fibers was similar than observed before the damage at all times studied [Fig. $1 B-E$; in $H$, one-way $\operatorname{ANOVA}\left(F_{(4,10)}=1.288\right.$, n.s. $\left.\left.p=0.3380\right)\right]$. As a complementary approach, we also examined the effect of this form of axonal damage on the entire innervation of the eye surface using Thy-1-YFP mice and fixed corneas. We measured the innervation density of control and injured corneas, and the coarse reinnervation pattern was similar to the more refined one observed in TRPM8 $(+)$ fibers after nerve damage (data not shown). 
A.
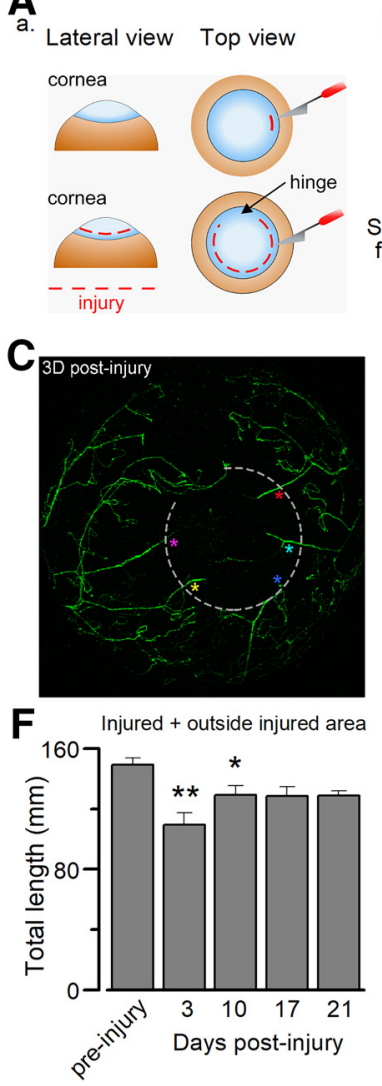
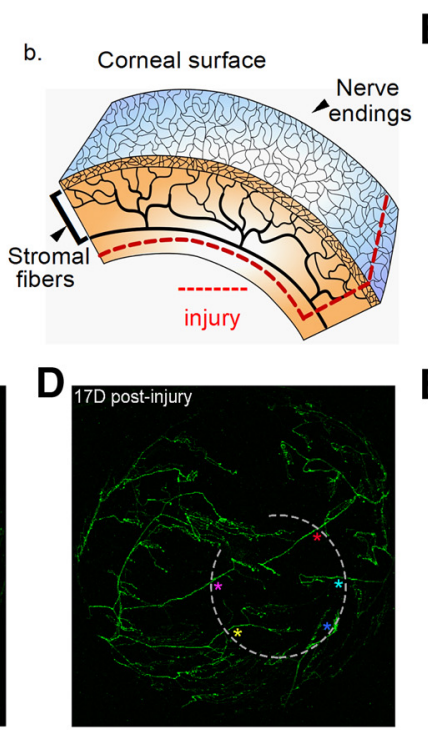

G

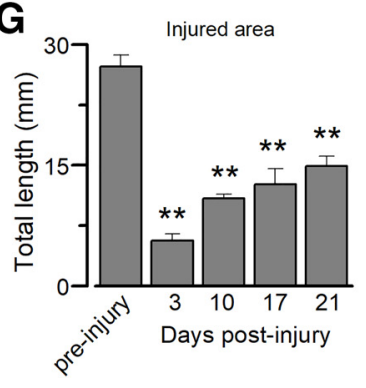

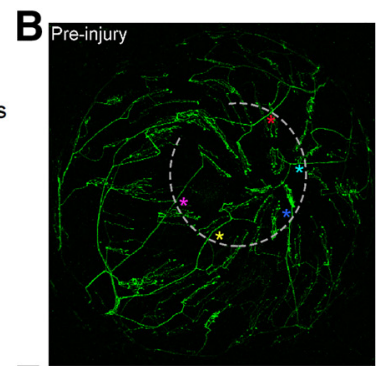

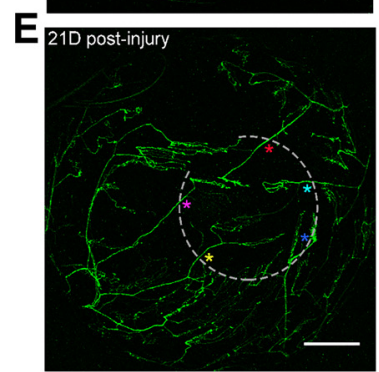

$\mathrm{H}$

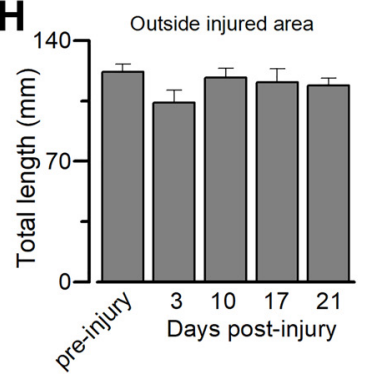

Figure 1. In vivo confocal tracking of whole corneal innervation by TRPM8 ${ }^{B A C}$-EYFP nerves. $A$, Schematic representation of the injury of corneal nerve fibers. Aa, Initial incision and extension of the surgical damage. $\boldsymbol{A} \boldsymbol{b}$, Scheme of corneal innervation (showing stromal nerve bundles and corneal subbasal nerve plexus), highlighting the deep injury of the fibers. $\boldsymbol{B}$, YFP fluorescence of intact corneal nerves (preinjury) in a TRPM8 ${ }^{B A C}$-EYFP mouse in vivo. Three TRPM8 ${ }^{\text {BAC }}$-EYFP mice where used for the tracking. $\boldsymbol{C}-\boldsymbol{E}$ Confocal tracking of the regeneration of axotomized corneal nerves at different time points in the same cornea: $(\boldsymbol{C}) 3 \mathrm{~d}$ after injury; (D) $17 \mathrm{~d}$ after injury; and $(\boldsymbol{E}) 21 \mathrm{~d}$ after injury. Light gray dotted lines indicate the axotomized area. The colored asterisks indicate different axotomized nerves at different time points. Scale bar, $500 \mu \mathrm{m}$. $\boldsymbol{F}$, Total length of corneal cold sensory nerves. Statistical significance was determined by one-way ANOVA $\left(F_{(4,10)}=5.878,{ }^{*} p=0.0110\right)$ followed by Holm-Sidak method (preinjury vs $3 \mathrm{~d}, t_{(14)}=4.847,{ }^{* *} p=0.0038$; preinjury vs $10 \mathrm{~d}, t_{(14)}=2.435,{ }^{*} p=0.0350$ ). $\mathbf{G}$, Total length of corneal cold sensory nerves in injured area. Statistical analysis was performed using one-way $\operatorname{ANOVA}\left(F_{(4,10)}=38.727\right.$, ${ }^{* * *} p<0.0010$ ) followed by Holm-Sidak method (preinjury vs $3 \mathrm{~d}, t_{(14)}=11.857,{ }^{* *} p=0.0038$; preinjury vs $10 \mathrm{~d}, t_{(14)}$ $=8.960,{ }^{* *} p=0.0029$; preinjury vs $17 \mathrm{~d}, t_{(14)}=8.014,{ }^{* *} p=0.0020 ;$ preinjury vs $\left.21 \mathrm{~d}, t_{(14)}=6.747,{ }^{*} p=0.0010\right)$. $\boldsymbol{H}$, Total length of corneal cold sensory nerves in intact areas. Statistical analysis was assessed with a one-way ANOVA $\left(F_{(4,10)}\right.$ $=1.288$, n.s. $p=0.3380)$. $\left({ }^{* *} p<0.05 ;{ }^{* *} p<0.01\right)$.

These results show that this type of corneal nerve injury induced a strong and rapid denervation of the damaged area with no significant changes in the periphery, and that 3 weeks after the injury the regenerating TRPM8 $(+)$ nerve fibers had innervated a significant portion of the wounded region.

\section{Peripheral axon damage in TG TRPM8 $(+)$ corneal neurons enhances their sensitivity to cold and menthol}

Trigeminal neurons innervating the cornea were identified by FM1-43 fluorescence (Fig. 2A) in both injured and sham mice. In cultured TG neurons obtained from intact mice, CCSNs responded to cooling ramps with $\left[\mathrm{Ca}^{2+}\right]_{i}$ rises and represented approximately $12 \%$ of total trigeminal primary sensory neurons (Fig. 2B,C). Notably, $21 \mathrm{~d}$ after surgical injury of the stromal corneal nerves, the proportion of CCSNs was significantly higher in TG cultures of injured mice compared with sham animals $\left(18.7 \%(58 / 310)\right.$ vs $12.2 \%(60 / 491) ;{ }^{*} p=0.0138$, Fisher's exact test; Fig. $2 C)$. We also noticed a larger amplitude of the $\left[\mathrm{Ca}^{2+}\right]_{i}$ response of CCSNs to cold in injured mice (Fig. $2 B, D$ ); Figure $2 D$

shows the difference in the average $\left[\mathrm{Ca}^{2+}\right]_{\mathrm{i}}$ rise evoked by cold in both populations. Cold thermoreceptors present a wide range of temperature sensitivities both in vivo and in vitro, and can be further segregated into LT and HT coldsensitive neurons, according to the onset of their firing response to cold being above or below $26.5^{\circ} \mathrm{C}$. Using this temperature value as a boundary, two distributions are evident, especially in large samples including hundreds of neurons (Thut et al., 2003; Madrid et al., 2009). The functional characterization of these populations has also been reported in corneal nerve fibers (González-González et al., 2017; Alcalde et al., 2018). In the present study, we kept this well established classification for canonical cold thermoreceptors, considering the same temperature value to separate both populations. The threshold temperature required to trigger $\left[\mathrm{Ca}^{2+}\right]_{\mathrm{i}}$ responses varied widely among CCSNs (Fig. 2E), and no significant differences between mean cold threshold values were observed when the whole population in both groups of mice were compared (threshold sham: $26.2 \pm 0.4^{\circ} \mathrm{C}, n=60$ vs injured: $26.9 \pm 0.5^{\circ} \mathrm{C}, n=58 ; t_{(116)}=1.298$, n.s. $p=0.1970$, unpaired Student's $t$ test). However, we noted that LT neurons from injured animals were slightly though significantly more sensitive to cold than those of sham-operated mice (threshold: injured $30.0 \pm 0.3^{\circ} \mathrm{C}, n=29$ vs sham $29.1 \pm 0.4^{\circ} \mathrm{C}$, $n=26 ; t_{(53)}=2.148,{ }^{\star} p=0.0362$, unpaired $t$ test; Fig. $2 F)$. Such difference was not apparent between HT-CCSNs of both groups of mice (threshold injured: $23.8 \pm 0.3^{\circ} \mathrm{C}$, $n=29$ vs sham: $23.9 \pm 0.3^{\circ} \mathrm{C}, n=34 ; t_{(61)}=$ 0.1781 , n.s. $p=0.8592$, unpaired $t$ test; Fig. $2 F)$.

Altogether, these results suggest that in injured mice there is an increase in the maximal cold-induced response of individual cold thermoreceptor neurons, a slightly higher temperature sensitivity of the LT-CCSNs subpopulation (cold thermoreceptors expressing high levels of TRPM8 channels; Madrid et al., 2009) and an increase in the population of CCSNs in response to surgical damage of corneal nerve fibers compared with sham animals.

Our observations are compatible with the idea that injury of peripheral axons increases the functional expression of TRPM8, enhancing the sensitivity of corneal TG neurons to cold. To further explore this possibility, we analyzed the responses of CCSNs of sham and injured mice to menthol, the canonical activator of TRPM8 channels. Menthol-sensitive neurons correspond to those CCSNs where this TRPM8 chemical activator induced a rise in $\left[\mathrm{Ca}^{2+}\right]_{\mathrm{i}}$ at $34^{\circ} \mathrm{C}$, or at least a shift in the cold threshold to warmer temperatures. Figure $3 A$ illustrates the $\mathrm{Ca}^{2+}$ imaging protocol used to evaluate the responses of CCSNs to cold, menthol, cold plus menthol and to the thermo-TRP activators AITC (TRPA1) and capsaicin (TRPV1), in a CCSN from a sham mouse. In Figure 3, $B$ and $C$, CCSNs from sham and injured mice were 
plotted individually, according to the initial temperature threshold in control solution from the highest to lowest threshold. In menthol-sensitive neurons, the thermal threshold under $100 \mu \mathrm{M}$ menthol is represented by green circles, and green triangles indicate that the particular neuron responded to menthol at basal temperature $\left(34^{\circ} \mathrm{C}\right)$. In menthol-insensitive CCSNs, the thermal threshold under the TRPM8 activator is represented by white circles. We found that $85 \%$ of CCSNs from the sham group (22/26) responded to menthol, whereas a positive response was observed in 100\% (29/29) of the corneal cold neurons of the injured mice, all of them presumably TRPM $8(+)$ $\left({ }^{*} p=0.0438\right.$, Fisher's exact test; Fig. $3 B-$ $D)$. Moreover, in TRPM8 $(+)$ corneal neurons of injured mice, $\left[\mathrm{Ca}^{2+}\right]_{\mathrm{i}}$ responses to cold and menthol, applied separately or combined, were larger than in sham-operated mice (Fig. 3E).

Earlier immunocytochemical and electrophysiological evidence suggested that TRPV1 and TRPA1 channels are expressed in different subpopulations of the cold-sensitive corneal neurons (Parra et al., 2010; Mergler et al., 2014). Indeed, perfusion of TRPM8 $(+)$ corneal neurons from sham mice with the TRPA1 agonist AITC or the TRPV1 agonist capsaicin evoked a $\left[\mathrm{Ca}^{2+}\right]_{\mathrm{i}}$ rise in an important percentage of the CCSNs (see an example in Fig. $3 A$ ). However, the incidence of positive responses to both agonists and the amplitude of $\Delta\left[\mathrm{Ca}^{2+}\right]_{\mathrm{i}}$ rises evoked in responsive neurons from sham operated and injured mice did not differ significantly (Fig. $3 F, G$ ), in contrast to the enhanced responses to cooling presented by the same neurons from the injured group (Fig. $3 H, I$ ).

The higher percentage of TRPM8 $(+)$ neurons observed in the TG of injured mice, and the potentiated response to cold and menthol of CCSNs, suggest a de novo expression of TRPM8 by neurons of other somatosensory modalities, which are known to exhibit passive and active membrane properties different from those of canonical TRPM8 $(+)$ cold neurons (Fang et al., 2005; González et al., 2017b). Canonical cold-thermoreceptors fire short duration action potentials $(\sim 1 \mathrm{~ms}$ at the half-amplitude of the depolarizing phase; Reid et al., 2002; Viana et al., 2002; Madrid et al., 2009; González et al., 2017b), whereas polymodal nociceptors fire long action potentials often with an inflection (or hump) in the falling phase ( $\sim 2 \mathrm{~ms}$ at the half-amplitude; Fang et al., 2005; González et al., 2017b). However, as shown in Table 1, the passive and active membrane properties of CCSNs from both groups of animals mainly exhibited the characteristic phenotype of cold thermoreceptor neurons (see Fig. 4A), with the sole exception of one neuron from an injured mouse that presented the characteristic hump of polymodal nociceptors in the repolarizing phase of the action potential.

The results described above suggest that CCSNs of both groups of animals correspond mainly to canonical LT and HT cold thermoreceptors, and support the idea that an increase in the 0.8592 , unpaired $t$ test).
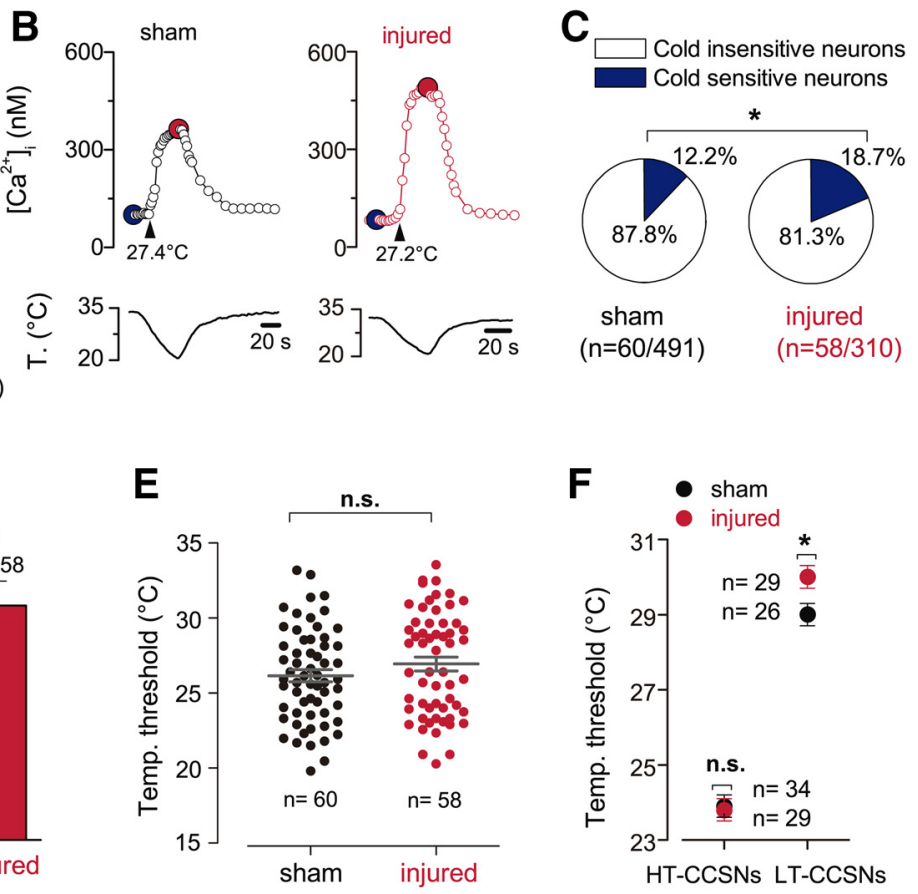

Figure 2. Altered cold sensitivity of corneal neurons induced by peripheral nerve damage. $\boldsymbol{A}$, Transmitted (top) and FM 1-43 labeling is $17 \mathrm{~d}$ after injury. $\boldsymbol{B}$, Cold-evoked $\left[\mathrm{Ca}^{2+}\right]_{i}$ response to a temperature ramp of two representative CCSNs from sham (left) (right) mice. Large dots indicate the basal (blue) and maximal (red) $\left[\mathrm{Ca}^{2+}\right]_{\mathrm{i}}$ during the cold stimulus. These neuron age ofCCNs in sham and injured mice. Size populations were compared using Fisher's exact test $\left.{ }^{*} p=0.0138\right)$. Summary bar

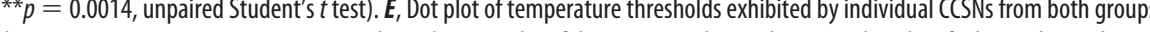
${ }^{*} p=0.0362$, unpaired $t$ test). Such difference was absent between HT-CCSNs of both groups of animals $\left(t_{(61)}=0.1781\right.$, n.s. $p=$

functional expression of TRPM8 channels in these subpopulations of trigeminal neurons underlies the increase of both, the percentage of cold-sensitive neurons and the amplitude of the individual responses to cold of corneal neurons from injured animals.

\section{TRPM8-dependent current density is increased in} cold-sensitive corneal neurons of injured mice

We explored the possibility of an increase in the functional expression of TRPM8 channels in corneal neurons of injured mice. We measured, at $-50 \mathrm{mV}$, the current evoked by cold $\left(I_{\text {cold }}\right)$ and by cold in the presence of $100 \mu \mathrm{M}$ menthol $\left(I_{\text {cold }+ \text { menthol }}\right)$, allowing the maximal activation of TRPM8 (Madrid et al., 2006, 2009; Mälkiä et al., 2007; González et al., 2017b). Figure 4B shows representative traces of $I_{\text {TRPM } 8}$ obtained from corneal neurons of sham (left) and injured (right) mice upon cold and cold plus menthol stimulation. Both $I_{\text {cold }}$ and $I_{\text {cold }+ \text { menthol }}$ were larger in injured than in sham animals $(-3.3 \pm 1.0$ and $-15.4 \pm 2.6$ $\mathrm{pA} / \mathrm{pF}$ in neurons from damaged mice $(n=12)$, vs $-1.1 \pm 0.3$ and $-6.3 \pm 0.8 \mathrm{pA} / \mathrm{pF}$ respectively in control condition $(n=12)$; $t_{(13)}=2.241,{ }^{\star} p=0.0431$ and $t_{(13)}=3.288,{ }^{* *} p=0.0059$; unpaired $t$ test with Welch's correction; Fig. $4 C$ ).

These results are consistent with those obtained by $\mathrm{Ca}^{2+} \mathrm{im}-$ aging and reinforce the notion that surgical damage of corneal nerves induces an increase in the expression of functional TRPM8 channels in cold thermoreceptor neurons innervating the cornea. 


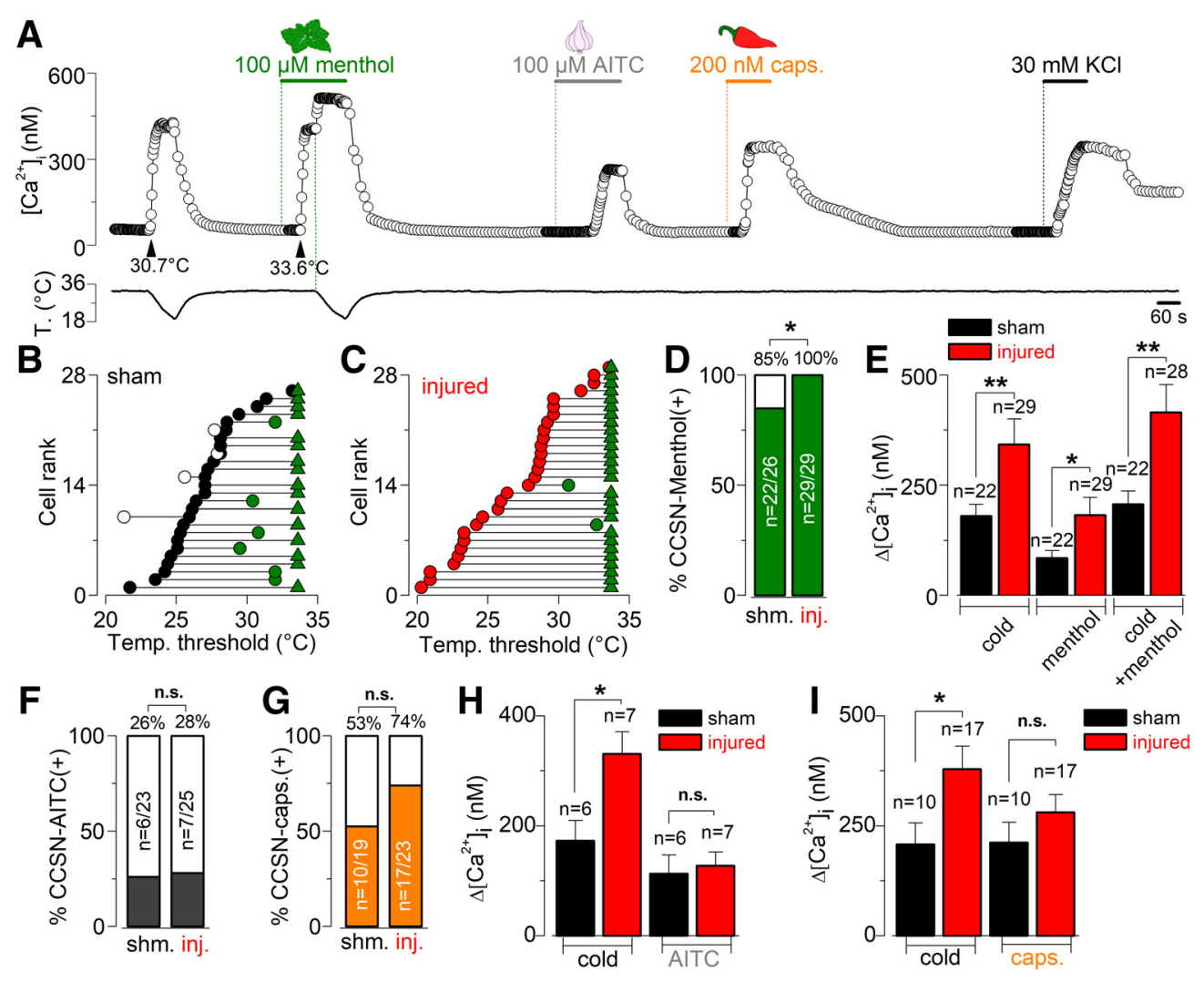

Figure 3. Evaluation of the responses of CCSNs from sham and injured mice to cold and chemical agonists of thermo-TRP channels. $A$, Protocol in $\mathrm{Ca}^{2+}$ imaging used to evaluate the responses of CCSNs to cold, menthol (100 $\mu \mathrm{m}$ ), cold plus menthol (TRPM8 activators), AITC (100 $\mu \mathrm{m}$; TRPA1 agonist) and capsaicin (200 nm; TRPV1 agonist). This trace corresponds to a CCSN from a sham animal. B, C, Dot plots of the effect of $100 \mu \mathrm{m}$ menthol on the cold-evoked temperature threshold in 26 control CCSNs (black circles) and 29 injured CCSNs (red circles). These neurons have been plotted according to the initial temperature threshold in control solution from lowest to highest temperatures. The shift in thermal threshold in mentholsensitive neurons is represented by green circles, and green triangles indicate the neurons that respond to menthol at $34^{\circ} \mathrm{C}$. The thermal threshold of menthol-insensitive CCSNs is represented by white circles. $\boldsymbol{D}$, Bar graph showing the percentage of menthol-sensitive (green) and menthol insensitive (white) CCSNs in both populations ( ${ }^{*} p=0.0438$, Fisher's exact test). $\boldsymbol{E}$, Bar graph summarizing the mean amplitude of cold-, menthol-, and cold plus menthol-induced responses of CCSNs from control (black) and injured (red) mice (cold: $t_{(49)}=$ $3.103,{ }^{* *} p=0.0031$, unpaired $t$ test; menthol and cold plus menthol: $t_{(44)}=2.484,{ }^{*} p=0.0169$ and $t_{(46)}=3.161,{ }^{* *} p=0.0028$ respectively; unpaired $t$ test with Welch's correction). $\boldsymbol{F}, \mathbf{G}$, Bar graphs showing the percentage of the AITC-sensitive (gray) and AITC-insensitive (white) and the capsaicin-sensitive (orange) and capsaicin-insensitive populations (white) of CCSNs in both groups (n.s. $p=1.0000$ (AITC) and $p=0.2023$ (Caps), Fisher's exact test). $\boldsymbol{H}, \boldsymbol{I}$, Bar graphs summarizing the mean amplitude of cold-and AITC-induced responses and coldand capsaicin-induced responses in CCSNs from sham (black bar) and injured (red black) groups respectively $\left(\operatorname{In} \boldsymbol{H}, t_{(11)}=2.304,{ }^{*} p=0.0417\right.$, and $t_{(11)}=0.1762$, n.s. $p=0.8633 ;$ In $I, t_{(25)}=2.388,{ }^{*} p=0.0247$, and $t_{(25)}=1.280$, n.s. $p=0.2123 ;$ unpaired $t$ test $)$.

Table 1. Active and passive membrane properties of retrogradely labeled CCSNs

\begin{tabular}{lllllllll}
\hline $\operatorname{CCSNs}$ & $\begin{array}{l}\text { Temperature } \\
\text { threshold }\left({ }^{\circ} \mathrm{C}\right)\end{array}$ & $\begin{array}{l}\text { Resting } \\
\text { potential }(\mathrm{mV})\end{array}$ & $\begin{array}{l}\text { Input } \\
\text { resistance }(\mathrm{M} \Omega)\end{array}$ & $\begin{array}{l}\text { Rheobase } \\
\text { current (pA) }\end{array}$ & $\begin{array}{l}\text { Spike } \\
\text { duration }(\mathrm{ms})\end{array}$ & $\begin{array}{l}\text { Inward } \\
\text { rectification index (\%) }\end{array}$ & $\begin{array}{l}\text { Firing frequency } \\
2 \times \text { rheobase (Hz) }\end{array}$ & $\begin{array}{l}\text { Tonic } \\
\text { firing pattern (\%) }\end{array}$ \\
\hline Sham $(n=18)$ & $27 \pm 0.7$ & $-48 \pm 2$ & $372 \pm 41$ & $79 \pm 19$ & $0.7 \pm 0.1$ & $53 \pm 4$ & $46 \pm 13$ & $56(10 / 18)$ \\
Injured $(n=22)$ & $27 \pm 0.7$ & $-49 \pm 2$ & $345 \pm 44$ & $86 \pm 12$ & $0.6 \pm 0.1$ & $52 \pm 3$ & $45 \pm 8$ & $45(10 / 22)$ \\
$t$ test & $p=0.8853$ & $p=0.7956$ & $p=0.6618$ & $p=0.6338$ & $p=0.3923$ & $p=0.8425$ & $p=0.9601$ & $p=0.7512^{a}$ \\
\hline
\end{tabular}

Temperature threshold was determined by using $\mathrm{Ca}^{2+}{ }^{2+}$ imaging $\left(t_{(38)}=0.1452\right.$, n.s. $\left.p=0.8853\right)$. Resting potential was measured at $I_{\text {hold }}=0 \mathrm{pA}\left(t_{(38)}=0.2608\right.$, n.s. $\left.p=0.7956\right)$. Input resistance was determined measuring the voltage drop induced by a hyperpolarizing current step to $-120 \mathrm{mV}\left(I_{\text {hold }}=0 \mathrm{pA}\right)\left(t_{(38)}=0.4408\right.$, n.s. $\left.p=0.6618\right)$. Rheobase current was determined as the minimal current required to trigger an action potential with a $10 \mathrm{~ms}$ depolarizing current pulse $\left(t_{(38)}=0.4801\right.$, n.s. $\left.p=0.6338\right)$. Spike duration was measured at half the amplitude of the first action potential evoked by a depolarizing current pulse $\left(t_{(38)}=0.8652\right.$, n.s. $\left.p=0.3923\right)$. Inward rectification index was evaluated as $100 \times\left(V_{\text {peak }}-V_{\text {steady-state }}\right) / V_{\text {peak }}$ during the voltage drop induced by a hyperpolarizing current pulse of $500 \mathrm{~ms}$ reaching a peak voltage around $-120 \mathrm{mV}\left(t_{(38)}=0.1999\right.$, n.s. $\left.p=0.8425\right)$. Firing frequency was calculated from the number of spikes at $2 \times$ rheobase current counted in a $500 \mathrm{~ms}$ period $\left(t_{(38)}=0.0503\right.$, n.s. $\left.p=0.9601\right)$. Student's $t$ test for independent samples. Tonic firing pattern corresponds to sustained action potential firing at $2 \times$ rheobase current during 500 ms pulses.

${ }^{a}$ Fisher's exact test.

\section{Brake current $I_{\mathrm{KD}}$ is unaffected by surgical corneal} nerve damage

A critical factor determining cold sensitivity of primary somatosensory neurons is the functional counterbalance of the outward $I_{\mathrm{KD}}$ and $I_{\mathrm{TRPM} 8}$ (Viana et al., 2002; Madrid et al., 2009; González et al., 2017b). In these neurons, the $I_{\mathrm{KD}}$ current works as an excitability brake, contributing to set the thermal threshold of both cold thermoreceptors and a subset of nociceptive neurons (Viana et al., 2002; Madrid et al., 2009; González et al., 2017b). This fast-activating slow-inactivating voltage-dependent $\mathrm{K}^{+}$current dampens the depolarizing effect of TRPM8 at subthreshold membrane potentials relative to those that fire action potentials (Storm, 1988; Viana et al., 2002; González et al., 2017b), shifting the cold threshold to lower temperatures and reducing the net response of neurons to temperature drops. We explored the possibility that damage-induced functional downregulation 

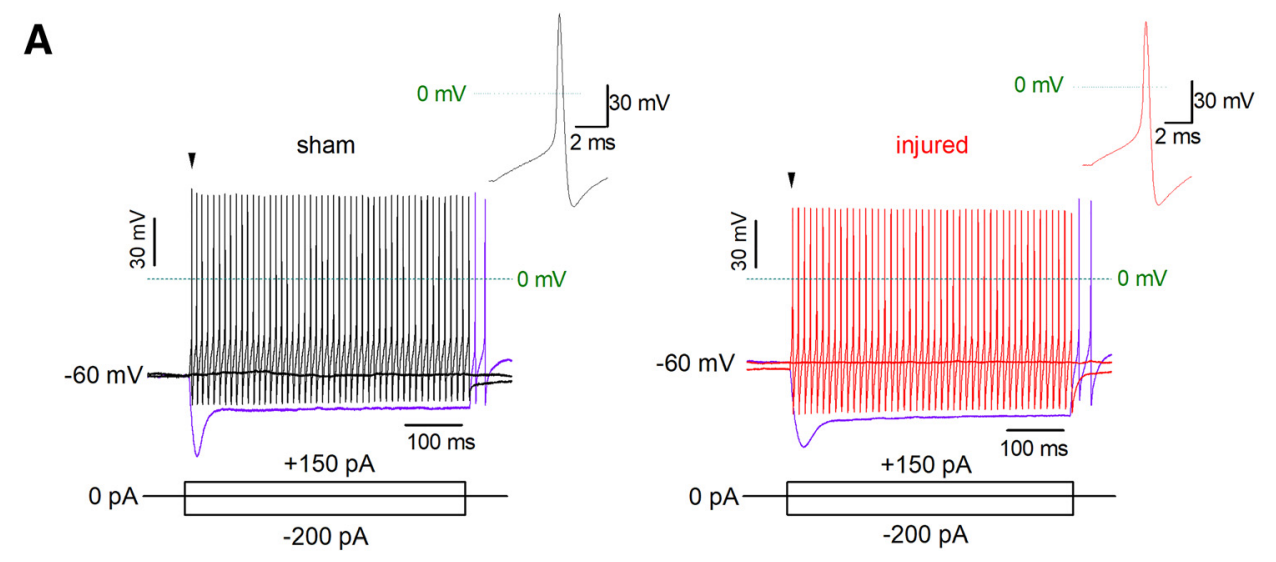

B
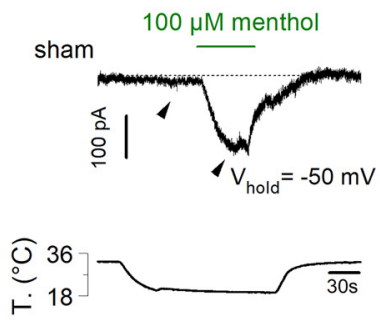

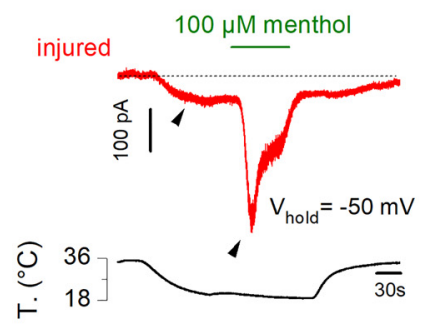

C

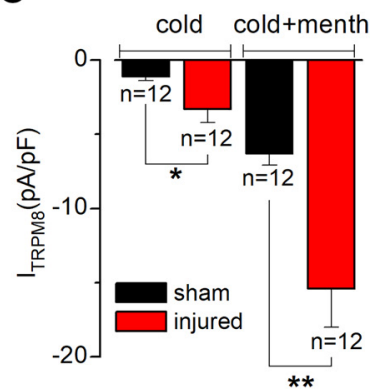

Figure 4. Electrophysiological properties and TRPM8-dependent current of CCSNs from sham and injured mice. $\boldsymbol{A}$, Voltage responses to 500 ms hyperpolarizing and depolarizing current pulses ( $I_{\text {ext }} ;$ bottom) from a representative sham (left) and injured (right) CCSNs. Note the fast tonic discharge, the sag at negative membrane potentials and the presence of rebound firing in both neurons (purple traces). Insets, First action potential of the neurons in A (black arrowheads). B, Simultaneous recording of whole-cell current (top) and bath temperature (bottom) during a long cooling step $\left(20^{\circ} \mathrm{C}\right)$ combined with application of menthol $(100 \mu \mathrm{M})$ in a representative $C\left(S \mathrm{~N}\right.$ from sham (left) and injured (right) mice $\left(V_{\text {hold }}=-50\right.$ $\mathrm{mV})$. C, Bar plot summarizing the mean cold- and cold + menthol-induced current densities in CCSNs isolated from control and injured animals $\left(t_{(13)}=2.241,{ }^{*} p=0.0431\right.$ and $t_{(13)}=$ $3.288,{ }^{* *} p=0.0059$; unpaired $t$ test with Welch's correction).

of potassium channels underlying $I_{\mathrm{KD}}$ also contributes to the slightly lower threshold and enhanced cold responsiveness of TRPM8(+) corneal neurons of injured mice. For this, we analyzed the effect of 4-AP (a well characterized $I_{\mathrm{KD}}$ blocker; Viana et al., 2002; Madrid et al., 2009; González et al., 2017b) on the temperature threshold and maximal cold-induced $\left[\mathrm{Ca}^{2+}\right]_{\mathrm{i}}$ response in CCSNs of sham-operated and injured animals. Figure $5 \mathrm{~A}$ shows the responses of a typical CCSN to the protocol used to study the reversible effect on thermal threshold induced by 100 $\mu \mathrm{M} 4$-AP. In this representative neuron from a sham mouse, the threshold of cold-evoked $\left[\mathrm{Ca}^{2+}\right]_{\mathrm{i}}$ rise was shifted $2.8^{\circ} \mathrm{C}$ to a higher temperature by the pharmacological suppression of the $I_{\mathrm{KD}}$. We found that the mean thermal thresholds of cold-sensitive neurons were shifted, to the same extent, to warmer temperatures in both groups in the presence of this $I_{\mathrm{KD}}$ blocker (from $26.7 \pm$ 0.6 to $30.0 \pm 0.6^{\circ} \mathrm{C}, n=25$, in control condition vs $27.0 \pm 0.7$ to $30.0 \pm 0.7^{\circ} \mathrm{C}, n=23$, in injured mice; $t_{(24)}=4.614,{ }^{* * *} p=0.0001$ and $t_{(22)}=4.077,{ }^{* *} p=0.0005$, respectively; paired $t$ test; Fig. $5 B$ ), suggesting that $I_{\mathrm{KD}}$ was not significantly affected by this form of corneal neuron damage. In Figure 5, $C$ and $D$, CCSNs from sham and injured mice were plotted individually, according to the initial temperature threshold from highest to lowest, and the thermal threshold of each neuron under $100 \mu \mathrm{M} 4$-AP is represented by blue circles. Cold thresholds of CCSNs were reduced by $1^{\circ} \mathrm{C}$ or more in the presence of $4-\mathrm{AP}$ in $76 \%$ of the control neurons (19/25) and in 70\% of the neurons from injured mice (16/ $23)$. In addition, we directly determined the $I_{\mathrm{KD}}$ density at -40 $\mathrm{mV}$ in CCSNs from sham and injured mice (a subthreshold membrane potential in these neurons, in which this brake current exerts its role), and we found that the mean $I_{\mathrm{KD}}$ densities in CCSNs from both groups were alike $[6.5 \pm 0.9 \mathrm{pA} / \mathrm{pF}$ in neurons from damaged mice $(n=14)$, vs $5.5 \pm 1.1 \mathrm{pA} / \mathrm{pF}$ in sham condition $(n=19) ; t_{(31)}=0.6132$, n.s. $p=0.5442$, unpaired $t$ test; Fig. $5 E]$.

Collectively, these results suggest that $I_{\mathrm{KD}}$ is unaffected by this form of corneal nerve damage, and that the post-injury functional phenotype of CCSNs is virtually independent of changes in this $\mathrm{K}^{+}$current.

Ongoing firing activity and sensitivity to cold and menthol of peripheral nerve endings of cold corneal neurons were higher after nerve damage

We recorded NTI activity in cold-sensitive nerve endings in the eyes excised from sham-operated mice (Fig. 6A, inset) and of animals that had been subjected to corneal nerve ablation $21 \mathrm{~d}$ earlier, measuring ongoing firing activity and responses to cold and menthol. Figure $6 \mathrm{~A}$ shows an example of the typical background NTI activity and the increased firing rate and change in the firing pattern evoked by cooling and menthol, recorded in a representative HB-LT cold thermoreceptor terminal of a control animal cornea. The peak in NTI activity during cooling ramps is followed by a prolonged silent period while the temperature returns to basal level (Carr et al., 2003; Parra et al., 2010). Samples of NTI activity in this nerve ending at different temperatures with and without menthol $(10 \mu \mathrm{M})$ are represented in Figure $6 B$. Figure $6 C$ shows representative examples of ongoing activity and 
A
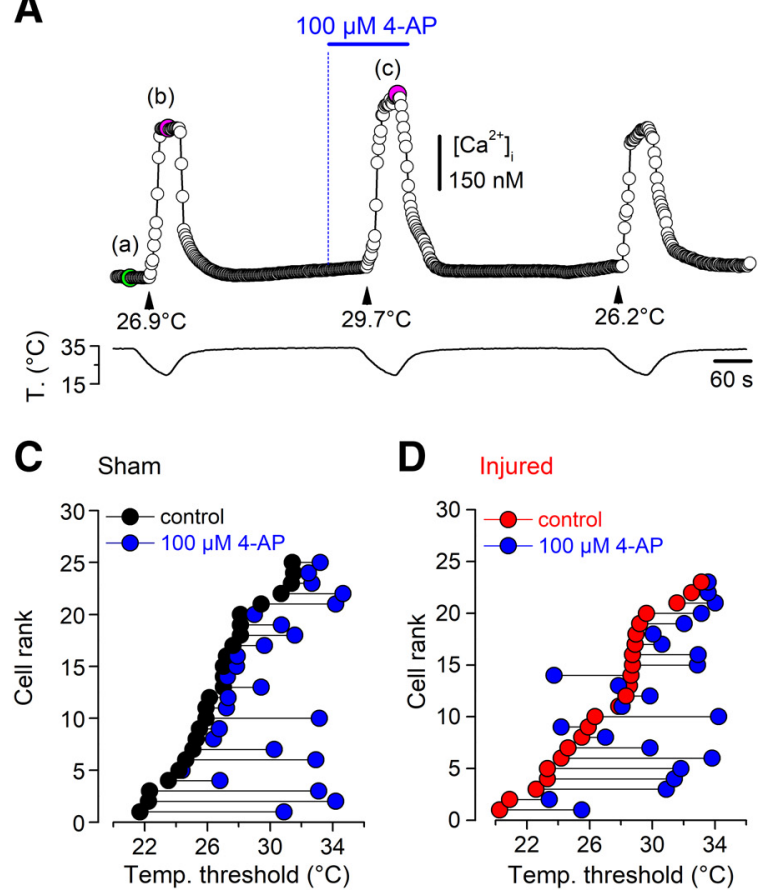

B

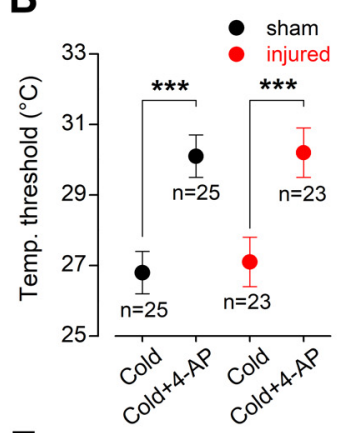

$\mathbf{E}$

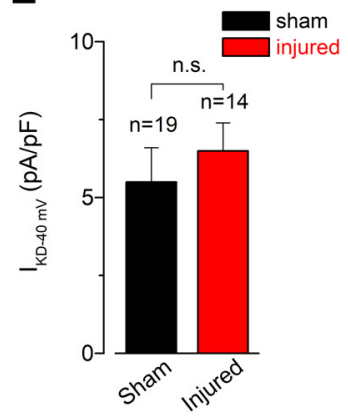

Figure 5. Effect of pharmacological suppression of $I_{\mathrm{KD}}$ on the thermal threshold of CCSNs from sham and injured mice. $A$, $\left[\mathrm{Ca}^{2+}\right]_{\mathrm{i}}$ response in a representative CCSN from a sham animal during three consecutive cooling stimuli, in control solution (first and third pulses) and in the presence of $100 \mu \mathrm{m}$ 4-AP (second pulse). The cold threshold of this neuron was shifted to higher temperatures by 4-AP, from 26.9 to $29.7^{\circ} \mathrm{C}$ (black arrowheads). The green dot in $\boldsymbol{A} \boldsymbol{a}$ indicates the basal level of $\left[\mathrm{Ca}^{2+}\right]_{\mathrm{i}}$ and the magenta dots in $\boldsymbol{A b}$ and $\boldsymbol{A c}$ indicate the maximal responses to cold in control and 4-AP conditions. Note the reversibility of the 4-AP-dependent effect. $\boldsymbol{B}$, Mean values of temperature threshold of CCSNs from control (black dots) and injured (red dot) mice in control conditions and in the presence of the inhibitor of $I_{K D}(4-A P)$. Note that the mean shift of the thermal threshold of both populations of $C \mathrm{CSN}$ by the suppression of $I_{\mathrm{KD}}$ was similar. Temperature threshold shifts after treatment with 4-AP in both populations were assessed using paired Student's $t$ test: $t_{(24)}=4.614{ }^{* * *} p=0.0001$ and $t_{(22)}=4.077,{ }^{* * *} p=0.0005$, respectively. $C, D$, Effect of $100 \mu \mathrm{m} 4-\mathrm{AP}$ on temperature threshold of cold-evoked responses in 25 CCSNs from sham group and 23 CCSNs from injured animals, displayed individually according to the initial cold threshold from highest to lowest. The thermal threshold under $100 \mu \mathrm{m}$ 4-AP is represented by blue circles. $\boldsymbol{E}$, Bar plot summarizing the mean $I_{\mathrm{KD}}$ current density at $-40 \mathrm{mV}$ in sham (black, $\left.n=19\right)$ and injured (red, $\left.n=14\right) \operatorname{CCSNs}\left(t_{(31)}=\right.$ 0.6132 , n.s. $p=0.5442$, unpaired $t$ test).

menthol-evoked firing rise $(10 \mu \mathrm{M})$ at $34^{\circ} \mathrm{C}$ in the same control and injured CCSNs. In sham mice, the mean background firing frequency of CCSNs was $3.5 \pm 0.2 \mathrm{~Hz}(n=54)$ at $34^{\circ} \mathrm{C}$ (Fig. $6 C, D)$, with $85 \%$ of the terminals exhibiting a beating pattern, similar to what we previously found in intact mouse corneas (Parra et al., 2010). In injured animals, the same proportion of cold thermoreceptor terminals (88\%) exhibited ongoing beating activity at $34^{\circ} \mathrm{C}$, but their mean firing frequency at this temperature $(5.2 \pm 0.4 \mathrm{~Hz}, n=32)$ was significantly higher than in sham corneas $\left(t_{(84)}=4.397,{ }^{* *} p<0.001\right.$, unpaired $t$ test; Fig. $\left.6 C, D\right)$. Likewise, menthol $(10 \mu \mathrm{M})$ induced a more pronounced increase in the background firing rate in corneas of injured mice than in those of sham animals $(10.1 \pm 0.8 \mathrm{~Hz}, n=8$, vs $6.8 \pm 0.7 \mathrm{~Hz}, n=$ $19, t_{(25)}=2.891,{ }^{* *} p=0.0078$, unpaired $t$ test; Fig. $\left.6 C, E\right)$. Additionally, the cooling threshold and the maximal frequency evoked by the cooling stimulus measured at day 21 in corneal cold-sensitive nerve terminals of injured and sham-operated mice were alike $\left(32.7 \pm 0.1^{\circ} \mathrm{C}, n=54\right.$, vs $32.2 \pm 0.2^{\circ} \mathrm{C}, n=32$; $t_{(34)}=2.292, p=0.0282$, unpaired $t$ test with Welch's correction), and the peak frequency responses were also similar (40.3 \pm $2.2 \mathrm{~Hz}, n=54$, vs $35.3 \pm 2.2 \mathrm{~Hz}, n=32 ; t_{(84)}=1.488$, n.s. $p=$ 0.1404 , unpaired $t$ test). Finally, we applied PBMC, a selective antagonist of TRPM8 with minimal unspecific effects on the voltage-gated channels responsible for the spike generation in primary somatosensory neurons (González et al., 2017b), to explore the contribution of TRPM8 channels on basal firing of corneal cold-sensitive nerve endings from control and injured eyes. We found that the ongoing activity was affected to the same extent by the pharmacological suppression of TRPM8 in both conditions (Fig. $6 F$ ), suggesting that the increase in basal firing observed in cold-sensitive nerve endings relies on this thermo-TRP channel.

Altogether, these results are consistent with the idea that deep injury of corneal nerve fibers induces upregulation of TRPM8 channels in cold thermoreceptors, increasing the background impulse firing and menthol sensitivity in these trigeminal neurons.

\section{Nerve-injured mice exhibit a higher basal tearing rate}

Because TRPM8-dependent sensory input from the eye surface is critical to maintain basal tearing production (Parra et al., 2010), we explored the possibility that changes in background activity in corneal cold thermoreceptor terminals affect basal tear flow. We determined the basal tearing rate, expressed as the mean wetted length of a phenol red-treated thread (in $\mathrm{mm}$ ) placed on the internal angle of the eye for $2 \mathrm{~min}$ in anesthetized mice (Fig. 7A). We found that, at room temperature, the tearing rate assessed $21 \mathrm{~d}$ after corneal damage in injured animals doubled the rate observed in sham mice $\left(3.7 \pm 0.5\right.$ vs $1.6 \pm 0.1 \mathrm{~mm} ; t_{(18)}=$ $3.846,{ }^{* *} p=0.0012$, unpaired $t$ test with Welch's correction; Fig. $7 B$ ). Moreover, $21 \mathrm{~d}$ after injury, the increase in basal tearing in response to nerve damage was strongly reduced by specifically blocking TRPM8 at the nerve endings of the eye surface using PBMC ( $3.9 \pm 0.4$ vs $2.6 \pm 0.4$ $\mathrm{mm}, n=10 ; t_{(9)}=2.899,{ }^{\star} p=0.0176$, paired $t$ test; Fig. $7 C$ ).

These results suggest that the prolonged changes in thermal and chemical sensitivity of TRPM8 $(+)$ corneal nerve fibers after regeneration might be linked to ocular sensory disturbances, dry eye sensation and intensified tearing in patients undergoing similar forms of corneal nerve damage.

\section{Mathematical model of NTI activity representing the dependence of $I_{\text {TRPM } 8}$ on the altered phenotype of corneal cold thermoreceptors caused by injury}

We sought to further explore the contribution of TRPM8 in cold thermoreceptor firing and cold- and menthol sensitivity, using a conductance-based mathematical model of cold sensitive neurons that includes this polymodal ion channel (Olivares and Orio, 2015; Olivares et al., 2015), one of the most significant molecular contributors to cold thermoreceptor physiology. We examined the effects of TRPM8-dependent current variations on the ongoing activity and the cold- and menthol-evoked responses using this model. 
Figure $8 A$ shows the result of simulating with two consecutive cold pulses (bottom trace), in the absence (left) and presence (right) of menthol. The mentholevoked effect was simulated by introducing a shift in the voltage for half-activation $\left(V_{1 / 2}\right)$ of TRPM8 (see Methods). The first two panels show the firing rate (spikes/s) and interspike intervals (ISIs) when the density of TRPM8 is considered to be normal (control condition), producing a basal activity around 4 spikes/s. The cold pulse causes a dramatic increase in the firing rate and more bursting events (seen in the ISI plot as ISI $<100 \mathrm{~ms}$ ), and when the temperature is brought back to $34^{\circ} \mathrm{C}$ there is a transient period of no activity, mimicking the experimental recordings (see Fig. 6). Simulation of menthol application causes a transient increase of activity followed by a steady firing rate higher than the basal rate (7-8 spikes/s). In the presence of menthol, a cold pulse evoked an important increase of action potential firing. The same simulation was repeated in the 'injured' condition, attained by increasing the maximal density of TRPM8, by 1.5 times compared with the control value. In this condition, the most evident effect is an increase of the basal firing rate to $\sim 6$ spikes/s. Both cold and menthol produce a potentiated increase of NTI activity. The temperature at which the cold pulse starts to increase firing (i.e., the threshold for cold-evoked activity) did not apparently change, as evidenced when the temporal activity profiles are compared, in tight correlation with our experimental observation.

The simulations described above were repeated with 20 different sets of parameters of the model (Table 2), to mimic different nerve endings and their biological variability. All the parameter sets produce a basal firing rate $\sim 4$ spikes/s (3.95 \pm $0.15)$, with their basal value of TRPM8 maximum conductance. Then, a range of TRPM8 conductance ratios from 0.90 to 1.75 times the basal value was explored, and the results are summarized in Figure $8, B-D$. The black line in these plots shows how the mean basal firing rate (Fig. $8 B$ ), maximum firing rate achieved during the cold pulse (Fig. 8C) and temperature threshold for the cold-induced response (Fig. 8D) depend on the maximum TRPM8 conductance (or expression level). The shadows in the plots represent the SD.

For each parameter set, the reference density (normalized to 1) is the value at which the model has an average basal firing frequency of 4 spikes $/ \mathrm{s}$ (at $34^{\circ} \mathrm{C}$ ) and is the value listed in Table 2. Figure 8, $E-G$, compares the data for normalized $g_{\text {TRPM8 }}=1$ ("control") vs 1.5 ("injured"), represented in Figure 8, $B-D$, as black and red dashed lines, respectively. When the TRPM8 density is increased, unpaired $t$ test).

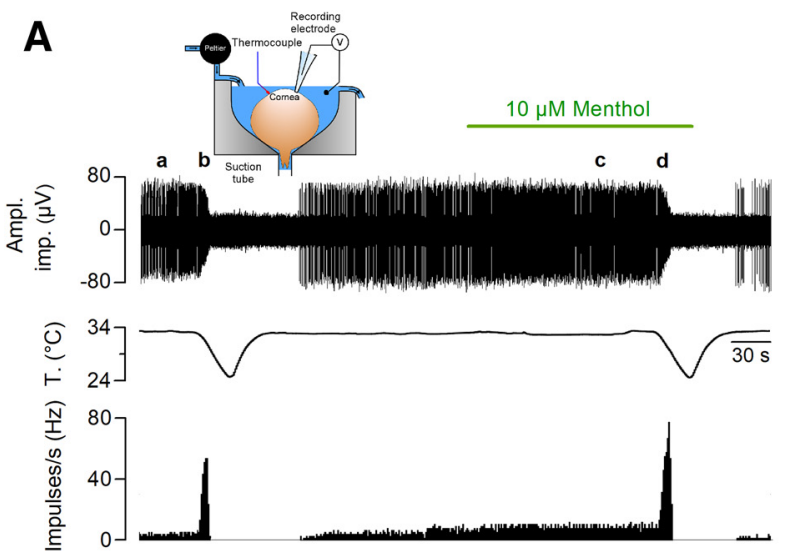

B
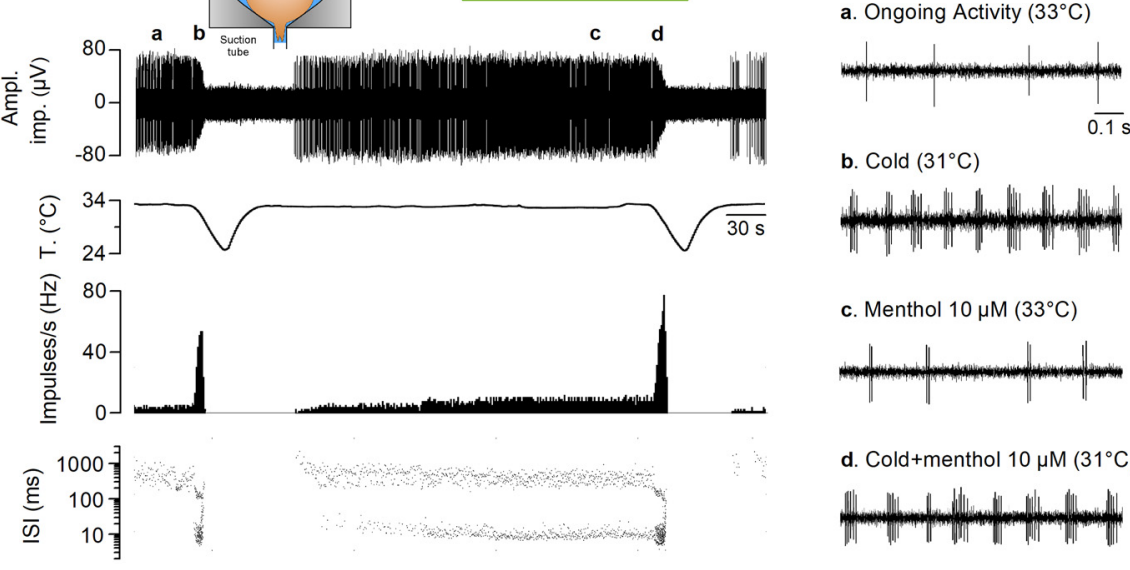

b. Cold $\left(31^{\circ} \mathrm{C}\right)$

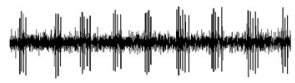

c. Menthol $10 \mu \mathrm{M}\left(33^{\circ} \mathrm{C}\right)$

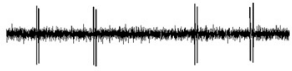

d. Cold+menthol $10 \mu \mathrm{M}\left(31^{\circ} \mathrm{C}\right.$
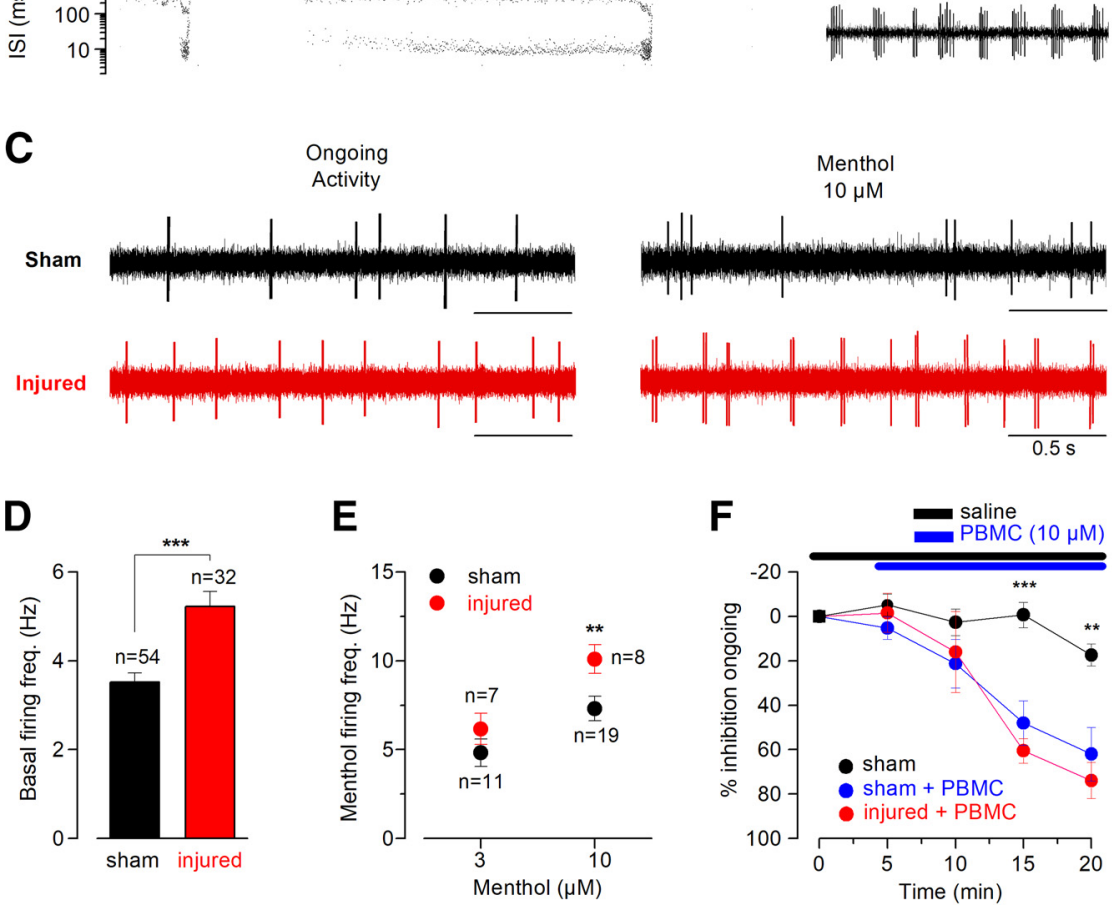

Figure 6. Ongoing activity and cold- and menthol-evoked responses of cold sensitive nerve terminals in sham and injured mice. $\boldsymbol{A}$, Traces from top to bottom are simultaneous recordings of NTI activity and temperature, NTI mean impulse rate (impulses per second $(\mathrm{Hz})$ ), and ISI values (log scale). Inset, Experimental arrangement used to record NTI activity from isolated mouse eye in vitro. $\boldsymbol{B}$, Changes in NTI frequency induced by cooling, menthol and cold plus menthol in the same control eye in $\boldsymbol{A}$. $\boldsymbol{B} \boldsymbol{a}$ to $\boldsymbol{B} \boldsymbol{d}$, Samples of NTI activity at different temperatures, with and without menthol (10 $\mu \mathrm{m})$ for the nerve ending in $\boldsymbol{A}$. C, Representative traces of basal activity in cold-sensitive corneal nerve endings from sham (black trace) and injured (red trace) mice. Note the augmented ongoing firing activity and menthol-evoked response in the CCSN from an injured mouse. $D$, Quantification of mean basal activity of cold-sensitive corneal nerve endings in sham and injured eyes (basal temperature: $34^{\circ} \mathrm{C} ; t_{(84)}=4.397,{ }^{* * *} p<0.001$, unpaired $t$ test). $\boldsymbol{E}$, Dot plot summarizing the average 3 and $10 \mu \mathrm{m}$ menthol-evoked responses in corneal nerve endings from control (black circles) and injured (red circles) mice ( $3 \mu \mathrm{m}: t_{(16)}$ $=1.131$, n.s. $p=0.2747$, and $10 \mu \mathrm{M}: t_{(25)}=2.891,{ }^{* *} p=0.0078$; unpaired $t$ test). $\boldsymbol{F}$, Effect of PBMC (specific TRPM8 blocker) on ongoing NTI activity of cold-sensitive corneal nerve endings from control and injured mice (sham with and without PBMC: $t_{(14)}=4.249,{ }^{* *} p=0.0008$ (15 min, $n=8$ nerve endings for each condition) and $t_{(8)}=3.432,{ }^{* *} p=$ 0.0089 (20 min, $n=5$ nerve endings for each condition); unpaired $t$ test). Note that the ongoing activity is strongly affected by PBMC in both groups (sham with PBMC vs injured with PBMC: $t_{(10)}=0.856, n . s . p=0.4118(15 \mathrm{~min}, n=8$ and $n=4$ nerve endings, respectively) and $t_{(7)}=0.741$, n.s. $p=0.4827$ ( $20 \mathrm{~min}, n=5$ and $n=4$ nerve endings respectively);

the basal firing rate increases (Fig. $8 E$, vehicle, $t_{(38)}=9.890$, ${ }^{* * *} p<0.001$; unpaired $t$ test) as well as the maximum response to cold (Fig. $8 F ; t_{(38)}=2.830,{ }^{\star *} p=0.0074$ ), whereas the thermal threshold is not affected, changing by $1^{\circ} \mathrm{C}$ or less (Fig. $8 G ; t_{(38)}=$ 0.355 , n.s. $p=0.7200$; unpaired $t$ test). In the presence of menthol (green lines in Fig. $8 B, C$ ), rising TRPM8 conductance also in- 
A

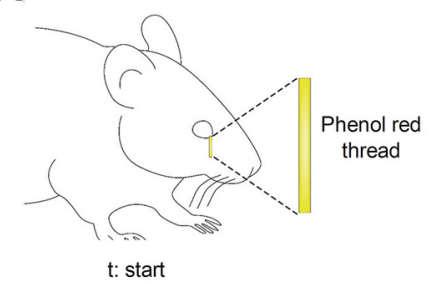

B

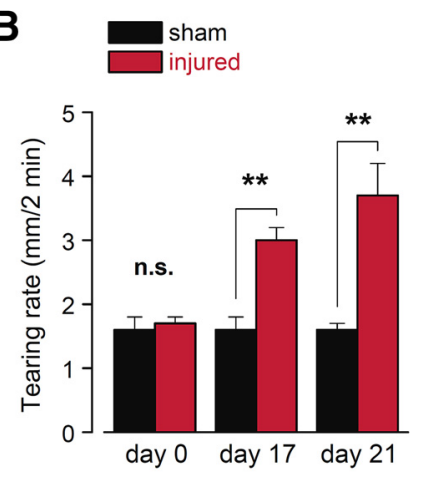

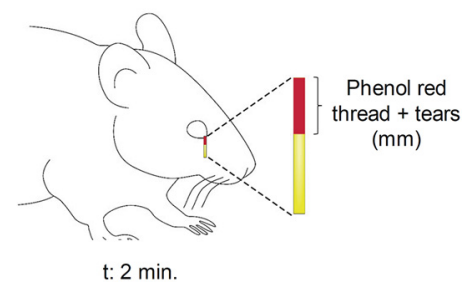
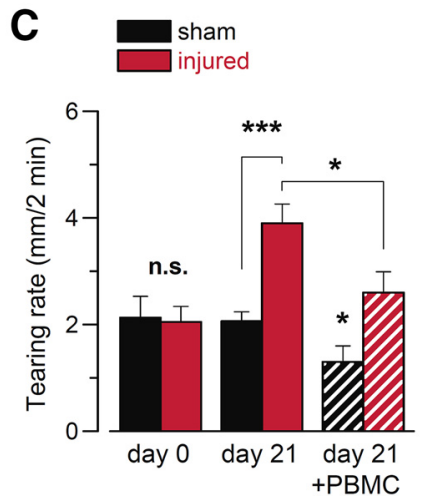

Figure 7. Changes in basal tear secretion rate in response to corneal nerve damage. $\boldsymbol{A}$, Schematic representation of the measurement of tearing rate by phenol red thread test in mice. $\boldsymbol{B}$, Basal tearing rate, expressed as the mean wetted length of the phenol red-treated thread in $\mathrm{mm}$ after $2 \mathrm{~min}$, measured in anesthetized mice $\left(n=16\right.$ in each condition; $t_{(30)}=0.0425$, n.s. $p=$ 0.9664 (day 0 ), $t_{(30)}=3.473,{ }^{* *} p=0.0016$ (day 17), unpaired $t$ test, and $t_{(18)}=3.846,{ }^{* *} p=0.0012$ (day 21), unpaired $t$ test with Welch's correction). C, Basal tearing rate, expressed as the mean wetted length of the phenol red-treated thread in $\mathrm{mm}$ after 2 min, measured in a different set of anesthetized mice. At day 21, the graph shows the mean tearing rate in sham $(n=9)$ and injured ( $n=10)$ animals, before (solid bars) and after (dashed bars) the application of $20 \mu \mathrm{m} \mathrm{PBMC}$ on the corneal surface. ( $t_{(17)}$ $=0.2452$, n.s. $p=0.8092$ (day 0), unpaired $t$ test, and $t_{(12)}=4.753,{ }^{* * *} p=0.0005$ (day 21), unpaired $t$ test with Welch's correction; $t_{(8)}=2.485,{ }^{*} p=0.0378$ (day 21, sham mice before and after PBMC), and $t_{(9)}=2.899,{ }^{*} p=0.0176$ (day 21, injured group before and after PBMC), paired $t$ test).

creases the basal firing rate (Fig. $8 E$, menthol, $t_{(38)}=2.800,{ }^{* *} p=$ 0.0080 ) and the response to cold (Fig. $8 F ; t_{(38)}=2.940,{ }^{* *} p=$ 0.0056 ; unpaired $t$ test). Therefore, our experimental measurements are closely mimicked by the mathematical model, supporting the notion that an increase of the maximum TRPM8 conductance is sufficient to reproduce the phenotype of TRPM8 $(+)$ corneal cold thermoreceptors after injury.

Collectively, our results support the interpretation that augmented impulse activity in corneal cold sensitive neurons following peripheral axon injury is mainly caused by an increase of TRPM8 channel expression in these neurons. A schematic representation of our results before and after peripheral injury is shown in Figure 9.

\section{Discussion}

Our study shows that surgical ablation of corneal nerves in the stroma causes complete loss of intraepithelial nerves followed by a rapid, albeit partial regeneration of TRPM8 $(+)$ axons. The cell bodies of injured TRPM8 $(+)$ corneal neurons showed a larger response to cooling or menthol, and their peripheral nerve terminals undergoing regeneration displayed a higher ongoing firing rate and enhanced responsiveness to menthol. Injuryevoked electrophysiological alterations in these neurons appear to be the consequence of an upregulation of TRPM8 channels caused by axotomy, without parallel changes in $I_{\mathrm{KD}}$, or expression of TRPV1 or TRPA1. This enhanced excitability and high background impulse firing of TRPM8(+) CCSNs mechanistically explains the rise of the basal tearing rate observed in injured mice.

The pattern of regenerative growth shown by identified TRPM8 $(+)$ thermoreceptor fibers after surgical axotomy is essentially the same as that recently reported for corneal fibers of all sensory modalities after excimer laser ablation of the central cornea (Bech et al., 2018). This suggests that TG neurons of different sensory modalities share the general cellular mechanisms governing the anatomical distribution plan of regenerating axons after injury. Disturbances in the expression, trafficking and kinetics of transducing, ligand- and voltage-gated channels in sensory ganglion neurons leading to membrane excitability changes after different types of peripheral axon injury are well documented (Waxman and Zamponi, 2014; Busserolles et al., 2016; Basso and Altier, 2017). Twenty-one days after mechanical cutting of stromal axons in young adult mice, we observed a significant increase in the background nerve impulse activity of corneal cold thermoreceptor terminals recorded within the denervated area. We also found an increased proportion of TRPM8 $(+)$ corneal neurons in the TG, and a larger $I_{\text {cold }}$ and $I_{\text {cold }+ \text { menthol }}$ in injured compared with sham mice, with more pronounced $\left[\mathrm{Ca}^{2+}\right]_{\mathrm{i}}$ responses to cold and menthol, attributable to a higher density of TRPM8 channels. This was the main change in transducing channels functional expression found in the cell body of corneal cold thermoreceptor neurons following axotomy at the stroma, whereas the responses to stimulation by agonist of TRPV1 or TRPA1, two channels that coexpress to different extents with TRPM8 in a fraction of the cold thermoreceptors, remained unaltered. Moreover, the Kv1 channels responsible for the brake current $I_{\mathrm{KD}}$, another key ionic mechanism influencing membrane excitability of cold sensory neurons (Viana et al., 2002; Madrid et al., 2009; González et al., 2017a,b), was not apparently modified.

We cannot discard variations in other channels involved in the modulation of impulse firing that were not explored in this study. For instance, cold hypersensitivity in oxaliplatin-induced neuropathy has been related to a remodeling of TREK-1, TRAAK, and HCN channel expression in TRPM8 $(+)$ nociceptors (Descoeur et al., 2011). $\mathrm{Na}_{\mathrm{v}} 1.6$ has also been proposed as a key $\mathrm{Na}_{\mathrm{v}}$ isoform involved in oxaliplatin-induced cold allodynia (Deuis et al., 2013), a sensory alteration involving TREK-2 (Pereira et al., 2014) and $\mathrm{K}_{\mathrm{v}} 7.2-7.3$ channels (Abd-Elsayed et al., 2015), to name a few (Lolignier et al., 2016). However, our evidence suggests that the upregulation of TRPM8 is the main functional disturbance underlying the electrophysiological changes observed in corneal cold thermoreceptors following mechanical injury of their parent axons at the deep level of the anterior corneal stroma; it also suggests that an increase in TRPM8 channels alone can explain the phenotype we observed in injured animals. 


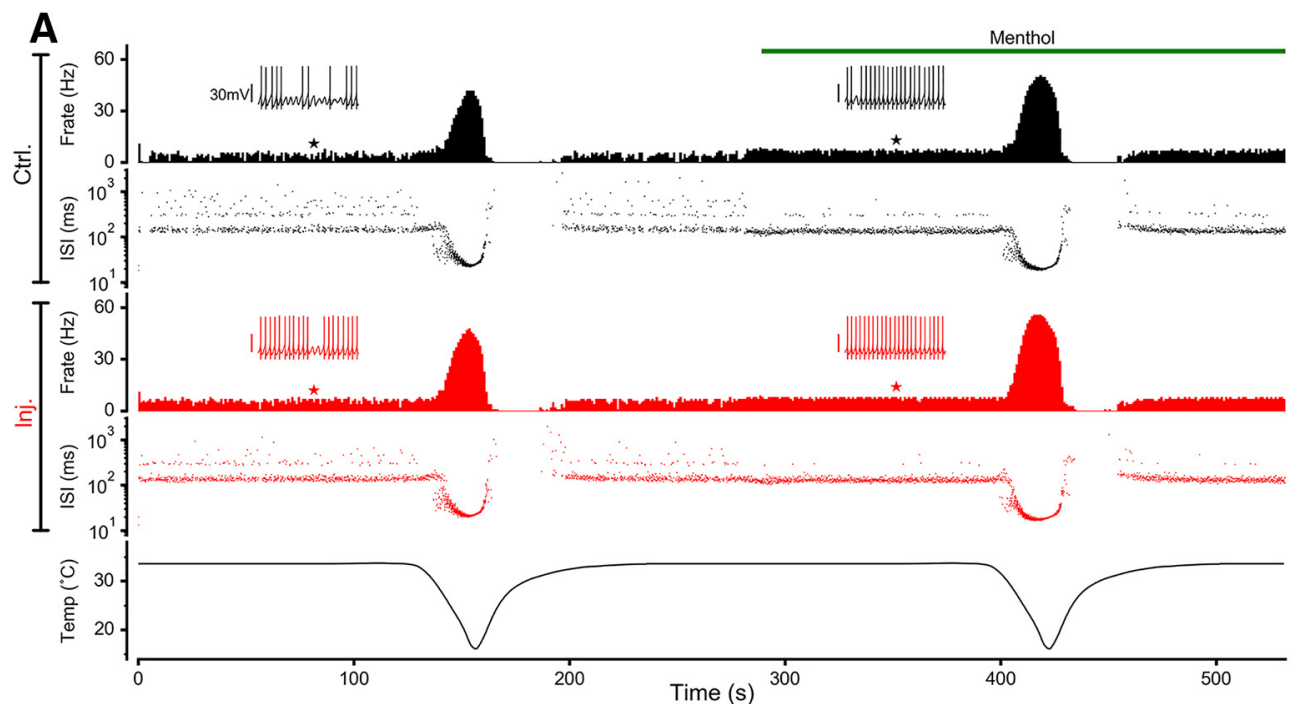

B

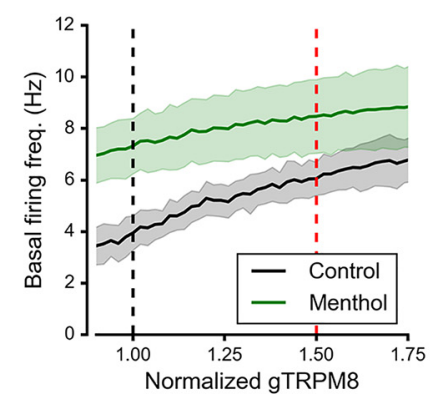

E

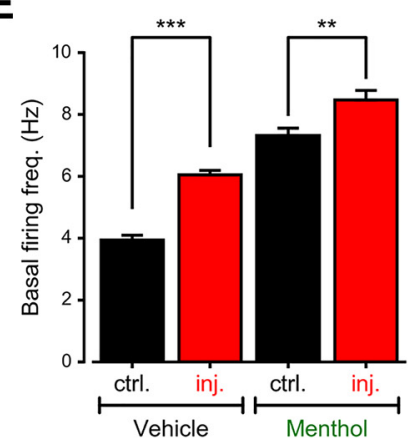

C

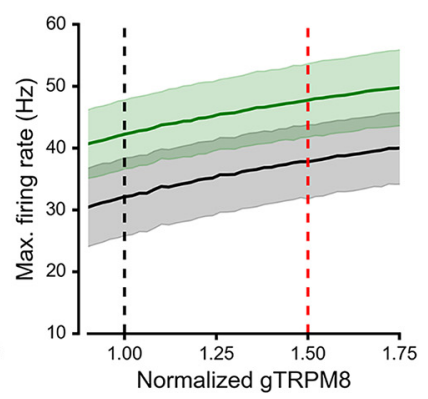

$F$

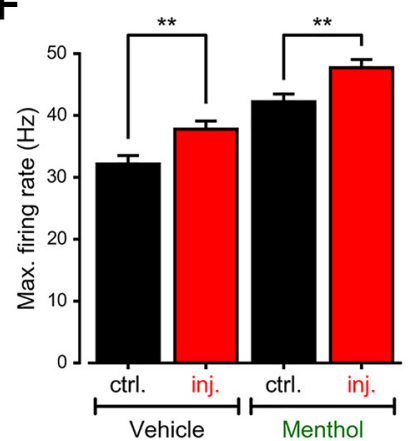

D

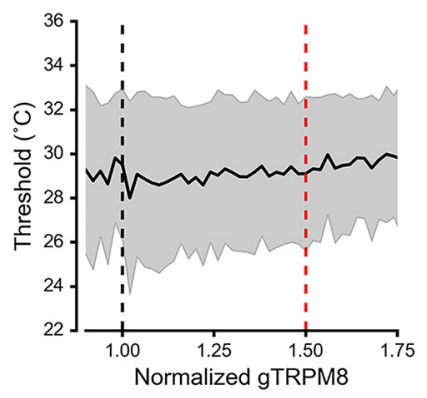

G

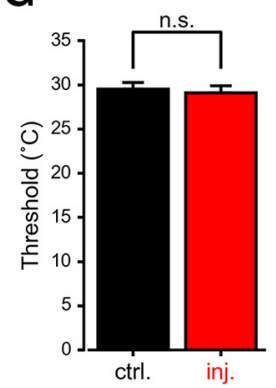

Figure 8. Mathematical model of cold-sensitive neurons with different $I_{\text {TRPM8 }}$ densities. A, Simulated activity of the model exposed to the temperature trace depicted at the bottom, and menthol stimulus simulated as a shift in the voltage for half-activation of TRPM8 (see methods). The top rows show the firing rate (F. rate; spikes/s) and the ISIs (log scale) during simulation, for a model considered as the "control" ( $\sim 4$ spikes $/ \mathrm{s}$ at $34^{\circ} \mathrm{C}$ ). The middle rows show the firing rate and ISIs for the same model with the TRPM 8 increased by a factor of 1.5 . Insets correspond to $3 \mathrm{~s}$ of simulated $V_{\text {memb }}$ at the times indicated by filled stars. $\boldsymbol{B}$, Average (lines) $\pm S D$ (shadows) of firing rate at $34^{\circ} \mathrm{C}$ for 20 sets of parameters (different neurons; see Table 2) in the absence and presence of simulated menthol as a function of TRPM8 density. For each model, the density of TRPM8 maximal conductance is expressed as the ratio to the TRPM8 density that gives a firing rate $\sim 4$ spikes/s. C, Average and SD of maximum firing rate during the cold pulse as a function of the TRPM8 maximal density. $D$, Average and SD of the temperature threshold for cold-evoked activity increase. In B-D, black and red dashed lines indicate the values plotted in $\boldsymbol{E}-\boldsymbol{G}$. $\boldsymbol{E}-\boldsymbol{G}$, The same mean values as in $\boldsymbol{B}-\boldsymbol{D}$ are plotted for a better comparison of the values for "control" (normalized $g_{\text {TRPM } 8}=1$ ) versus "injured" (normalized $g_{\text {TRPM } 8}=1.5 ;{ }^{* *} p<0.01,{ }^{* * *} p<0.001$, n.S. $p>0.05$ ). Bars represent mean \pm SEM, $n=20 . \ln \boldsymbol{E}, t_{(38)}=9.890,{ }^{* * *} p<0.001$ for vehicle and $t_{(38)}=2.800,{ }^{* *} p=0.0080$ for menthol. In $\boldsymbol{F}, t_{(38)}=2.830,{ }^{* *} p=0.0074$ for vehicle and $t_{(38)}=2.940,{ }^{* *} p=0.0056$ for menthol. In $G_{,} t_{(38)}=0.355$, n.s. $p=0.7200$. Unpaired Student's $t$ test.

The changes in corneal cold thermoreceptor firing observed experimentally after peripheral axotomy were successfully reproduced with a mathematical model containing the different parameters that define the excitability of TRPM8 $(+)$ cold thermoreceptor neurons. In this model, an increase in TRPM8 channel density is sufficient to mimic our experimental observations, without requiring any other large adjustments to parameters or equations. This reinforces the critical importance played by the increased functional expression of TRPM8 to enhance the activity of injured corneal cold thermoreceptors, and validates the usefulness of our model as a tool not only to understand but also to predict relevant damage-triggered changes in dynamic and static responses. Moreover, since the cold threshold in primary somatosensory neurons appears to be more influenced by the brake current $I_{\mathrm{KD}}$ than by the density of TRPM8dependent current (González et al., 2017a,b; Pertusa and Madrid, 2017), the simulation is also consistent with the lack of large differences in mean thermal thresholds observed experimentally between intact and injured neurons. 
Table 2. Parameter sets used in the model

\begin{tabular}{|c|c|c|c|c|c|c|c|c|c|c|c|}
\hline \multirow[b]{2}{*}{ Set no. } & \multicolumn{6}{|c|}{$\mathrm{mS} / \mathrm{cm}^{2}$} & \multirow{2}{*}{$\frac{\times 10^{4}}{p_{\mathrm{Ca}}}$} & \multicolumn{2}{|l|}{$\mathrm{ms}$} & \multicolumn{2}{|l|}{$\mathrm{mV}$} \\
\hline & $g_{\mathrm{M} 8}$ & $g_{1}$ & $g_{\text {sd }}$ & $g_{\mathrm{sr}}$ & $g_{\mathrm{d}}$ & $g_{\mathrm{r}}$ & & $\tau_{\mathrm{Ca}}$ & $\tau_{\delta_{V}}$ & $\delta V_{\min }$ & $\delta V_{\text {max }}$ \\
\hline 1 & 2.3 & 0.27 & 0.29 & 0.20 & 3.7 & 5.0 & 1.8 & 23400 & 1300 & -160 & 215 \\
\hline 2 & 1.4 & 0.24 & 0.28 & 0.22 & 3.5 & 4.9 & 2.5 & 27500 & 1250 & -220 & 170 \\
\hline 3 & 0.9 & 0.21 & 0.35 & 0.31 & 3.0 & 4.4 & 1.3 & 24000 & 3100 & -230 & 250 \\
\hline 4 & 0.4 & 0.17 & 0.21 & 0.28 & 4.0 & 4.9 & 4.7 & 14000 & 8200 & -250 & 110 \\
\hline 5 & 0.5 & 0.16 & 0.20 & 0.28 & 3.9 & 4.7 & 5.2 & 14000 & 9600 & -225 & 150 \\
\hline 6 & 3.5 & 0.24 & 0.30 & 0.25 & 4.0 & 5.0 & 3.5 & 20000 & 1300 & -230 & 185 \\
\hline 7 & 4.3 & 0.22 & 0.25 & 0.21 & 3.9 & 5.0 & 3.2 & 40000 & 3500 & -150 & 170 \\
\hline 8 & 1.3 & 0.21 & 0.28 & 0.26 & 3.8 & 4.7 & 3.6 & 26000 & 4000 & -250 & 150 \\
\hline 9 & 3.5 & 0.27 & 0.32 & 0.20 & 2.8 & 4.9 & 3.4 & 23500 & 5000 & -190 & 235 \\
\hline 10 & 3.3 & 0.26 & 0.33 & 0.21 & 3.0 & 4.7 & 3.3 & 39000 & 9200 & -220 & 250 \\
\hline 11 & 3.2 & 0.18 & 0.21 & 0.23 & 2.5 & 3.4 & 4.6 & 24500 & 7000 & -230 & 240 \\
\hline 12 & 2.0 & 0.19 & 0.21 & 0.22 & 2.7 & 3.0 & 4.7 & 19000 & 15000 & -230 & 250 \\
\hline 13 & 2.7 & 0.20 & 0.21 & 0.20 & 2.4 & 2.3 & 5.5 & 24000 & 8300 & -250 & 230 \\
\hline 14 & 2.0 & 0.27 & 0.33 & 0.21 & 2.7 & 4.6 & 1.9 & 24000 & 5100 & -130 & 240 \\
\hline 15 & 1.3 & 0.28 & 0.34 & 0.20 & 3.3 & 4.7 & 1.4 & 38000 & 4100 & -140 & 240 \\
\hline 16 & 2.0 & 0.29 & 0.34 & 0.20 & 3.0 & 4.2 & 4.8 & 21500 & 1400 & -210 & 170 \\
\hline 17 & 1.4 & 0.28 & 0.34 & 0.20 & 3.1 & 5.0 & 3.8 & 18000 & 5400 & -150 & 190 \\
\hline 18 & 2.6 & 0.27 & 0.33 & 0.21 & 2.8 & 3.7 & 5.4 & 16000 & 9100 & -140 & 170 \\
\hline 19 & 1.6 & 0.23 & 0.25 & 0.20 & 4.0 & 5.0 & 5.8 & 19000 & 6250 & -220 & 170 \\
\hline 20 & 3.0 & 0.23 & 0.25 & 0.20 & 4.0 & 5.0 & 5.8 & 19000 & 6200 & -250 & 250 \\
\hline
\end{tabular}

$g_{\mathrm{M} 8}, g_{1}, g_{\mathrm{sd}}, g_{\mathrm{sr}}, g_{\mathrm{d}}$, and $g_{\mathrm{r}}$ are the maximum conductance densities of the respective ion currents (representative of the ion channel expression level). $p_{\mathrm{c}}$ is a parameter that control how much the TRPM 8 current contributes to an increase in $\left[\mathrm{Ca}^{2+}\right]_{\mathrm{i}}$ and channel desensitization. $\tau_{\mathrm{Ca}}$ and $\tau_{\delta \gamma}$ are the time constants for $\mathrm{Ca}^{2+}$ removal and for the desensitization process, respectively. $\delta V_{\min }$ and $\delta V_{\text {max }}$ are the maximum values for TRPM $8 V_{1 / 2}$ displacement due to $\mathrm{Ca}^{2+}$-dependent desensitization (see Olivares and Orio, 2015; Olivares et al., 2015).

Regenerating cold thermoreceptors displayed an enhanced ongoing activity 3 weeks after mechanical stromal parent axon's axotomy, a procedure that preserved only a few intact stromal branches in the hinge. This result contrasts with the low background activity in the majority of corneal cold terminals after a superficial excimer laser corneal lesion, where only the epithelium nerve branches and a fraction of the superficial stromal nerve trunks were destroyed (Bech et al., 2018). In this case, many parent axons maintained part of their complex branching tree intact, and only $20 \%$ of the recorded, regenerating cold nerve terminals exhibited abnormal background firing and lower threshold (i.e., higher sensitivity) to cooling stimuli, possibly corresponding to more severely injured axons. The different responsiveness of injured corneal cold thermoreceptors depending on the characteristics and/or location of the peripheral injury likely reflects a variable degree of impairment of the molecular and cellular processes governing the recovery of membrane excitability after distal axonal damage. Transcription factors play a pivotal role in changing the gene expression pattern in sensory neurons following injury (Raivich and Makwana, 2007). The transcription factor $c$-jun is strongly activated by deep stromal denervation of the cornea by wounds produced by $\mathrm{NaOH}$. This does not occur when damage is limited to the sub-basal axons and their epithelial branches surrounded only by epithelium cells, as in n-heptanol corneal epithelium wounds (De Felipe and Belmonte, 1999). We tentatively propose that gene overexpression depending on the location and extension of the axonal damage, determines the magnitude of cold thermoreceptor neuron's reaction to injury, explaining the more intense effect on background activity caused by deep mechanical injury than with superficial PRK injury of stromal nerves.

Therefore, final excitability disturbances of injured cold corneal nerves can be defined by the type of peripheral axon lesion. For instance, in DED, epithelium surface desiccation markedly alters the architecture and density of sub-basal corneal axons and epithelium terminals, both in experimental animals and humans, enhancing cell body excitability and ending's background firing of guinea pig TG cold thermoreceptors, three weeks after lachry- mal gland removal (Kovács et al., 2016b). This suggests that some degree of nerve damage is an important pathological consequence of DED. Nonetheless, in corneal cold neurons of teardeficient animals, cold- and menthol-evoked $\left[\mathrm{Ca}^{2+}\right]_{\mathrm{i}}$ responses and $I_{\text {TRPM8 }}$ were normal (Kovács et al., 2016a), whereas bigger sodium currents and decreased potassium currents were recorded. The apparent absence of a functional overexpression of TRPM8 in these DED cold neurons despite the morphological evidence of peripheral nerve damage suggests that in experimental DED corneas, enhanced ongoing firing of cold thermoreceptor terminals is due to dysregulation of voltage-gated sodium and potassium channels, rather than TRPM8. These alterations could be explained by the chronic corneal inflammation that develops in DED together with the desiccation-evoked nerve terminal damage (Kovács et al., 2016b; Pflugfelder et al., 2017). The inflammatory reaction orchestrated by immune cells around regenerating axons and TG neurons modify their transducing and encoding capacities. Locally released inflammatory cytokines cause altered trafficking and regulation of $\mathrm{Na}_{\mathrm{v}}$ and $\mathrm{K}_{\mathrm{v}}$ channels in corneal nerve endings and sensitization (Leffler et al., 2002; Pflugfelder et al., 2017). At the same time, they inhibit TRPM8 channel activity (Linte et al., 2007; Zhang et al., 2012), significantly depressing corneal cold thermoreceptor background firing, as reported in other experimentally-evoked inflammatory keratitis, where spontaneous corneal cold thermoreceptor firing appears depressed, in contrast to the inflammation-driven sensitization observed in polymodal nociceptors (Acosta et al., 2013, 2014). Higher excitability resulting from voltage-gated channel overexpression and inhibition of $I_{\text {TRPM } 8}$ currents possibly coexist when injury and inflammation are simultaneously present as in DED.

In healthy human corneas, temperature drops of $1-2^{\circ} \mathrm{C}$ initially evoke a sensation of cold that becomes unpleasant with more intense cooling; this has been attributed to the recruitment of LT- and HT- cold thermoreceptors, respectively (Acosta et al., 2001; Belmonte et al., 2015, 2017). Photorefractive surgery is accompanied by sensations of unpleasant dryness and pain that differ in intensity and time course (Litwak et al., 2002; Nettune 
A
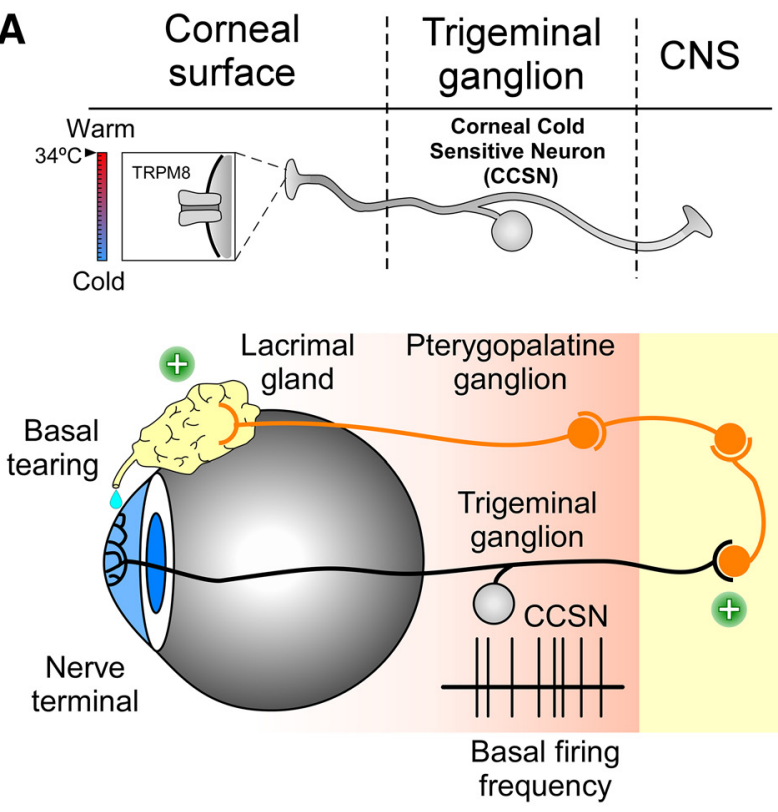

Control
B
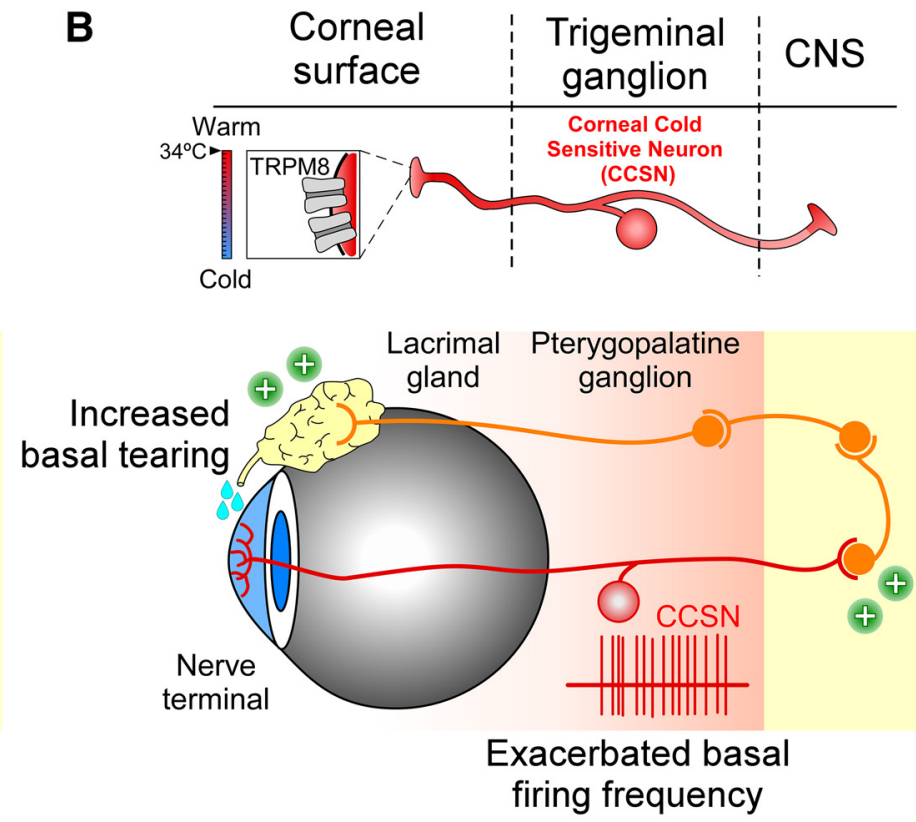

Injured

Figure 9. Schematic representation of TRPM8-dependent cold sensitivity and tearing in control and injured eyes. $\boldsymbol{A}, \boldsymbol{B}$, Top, Simplified representation of cold detection mechanisms in TRPM8(+) CCSNs. Boxes depict TRPM8 channels involved in the detection of cold stimuli in nerve terminals in sham (black and gray) and injured mice (red). Twenty-one days after damage, the expression of TRMP8 channels was higher in the corneal thermoreceptor neurons of injured mice than in control animals. The changes of label size and channel number reflect the variable expression of TRPM8. Bottom, Representation of the principal nerve corneal innervation by cold thermoreceptors and the neural circuit related to basal tear production. In control mice (left), the low basal firing frequency of TRPM8 (+) neurons (black record) maintains normal basal tearing. In injured mice (right), action potential firing of TRPM8(+) CCSNs is exacerbated due to an increase in the functional expression of TRPM8 channels in trigeminal neurons innervating this tissue, increasing basal tear production.

and Pflugfelder, 2010; Wang et al., 2014), depending on the surgical technique employed. Our results suggest that the perceptual quality of the discomfort accompanying post-refractive surgery is defined by variable alteration of background activity and thermal sensitivity of injured cold thermoreceptor neurons, depending on the type and location of damage to their corneal axons. In addition to their perceptual role, ocular surface TRPM8 $(+)$ cold thermoreceptors have been proposed to act as wetness sensors detecting evaporation-evoked corneal temperature oscillations, which adjust basal tear secretion and blinking rate, thereby preventing desiccation of the eye surface (Parra et al., 2010; Quallo et al., 2015; Belmonte et al., 2017). Indeed, after surgical injury of corneal nerves we detected an increased tearing rate that occurs in parallel with enhanced background firing of cold thermoreceptors endings, thus supporting a causal relationship between both processes.

\section{References}

Abd-Elsayed AA, Ikeda R, Jia Z, Ling J, Zuo X, Li M, Gu JG (2015) KCNQ channels in nociceptive cold-sensing trigeminal ganglion neurons as therapeutic targets for treating orofacial cold hyperalgesia. Mol Pain 11:45.

Acosta MC, Tan ME, Belmonte C, Gallar J (2001) Sensations evoked by selective mechanical, chemical, and thermal stimulation of the conjunctiva and cornea. Invest Ophthalmol Vis Sci 42:2063-2067.

Acosta MC, Luna C, Quirce S, Belmonte C, Gallar J (2013) Changes in sensory activity of ocular surface sensory nerves during allergic keratoconjunctivitis. Pain 154:2353-2362.

Acosta MC, Luna C, Quirce S, Belmonte C, Gallar J (2014) Corneal sensory nerve activity in an experimental model of UV keratitis. Invest Ophthalmol Vis Sci 55:3403-3412.

Alcalde I, Íñigo-Portugués A, González-González O, Almaraz L, Artime E, Morenilla-Palao C, Gallar J, Viana F, Merayo-Lloves J, Belmonte C (2018) Morphological and functional changes in TRPM8-expressing corneal cold thermoreceptor neurons during aging and their impact on tearing in mice. J Comp Neurol 526:1859-1874.
Almaraz L, Manenschijn JA, de la Peña E, Viana F (2014) TRPM8. In: Handbook of experimental pharmacology (Nilius B, Flockerzi V, eds), pp 547579. Berlin: Springer

Basso L, Altier C (2017) Transient receptor potential channels in neuropathic pain. Curr Opin Pharmacol 32:9-15.

Bech F, González-González O, Artime E, Serrano J, Alcalde I, Gallar J, Merayo-Lloves J, Belmonte C (2018) Functional and morphologic alterations in mechanical, polymodal, and cold sensory nerve fibers of the cornea following photorefractive keratectomy. Invest Ophthalmol Vis Sci 59:2281-2292.

Belmonte C, Gallar J (2011) Cold thermoreceptors, unexpected players in tear production and ocular dryness sensations. Invest Ophthalmol Vis Sci 52:3888-3892.

Belmonte C, Acosta MC, Gallar J (2004) Neural basis of sensation in intact and injured corneas. Exp Eye Res 78:513-525.

Belmonte C, Acosta MC, Merayo-Lloves J, Gallar J (2015) What causes eye pain? Curr Ophthalmol Rep 3:111-121.

Belmonte C, Nichols JJ, Cox SM, Brock JA, Begley CG, Bereiter DA, Dartt DA, Galor A, Hamrah P, Ivanusic JJ, Jacobs DS, McNamara NA, Rosenblatt MI, Stapleton F, Wolffsohn JS (2017) TFOS DEWS II pain and sensation report. Ocul Surf 15:404-437.

Brauchi S, Orio P, Latorre R (2004) Clues to understanding cold sensation: thermodynamics and electrophysiological analysis of the cold receptor TRPM8. Proc Natl Acad Sci U S A 101:15494-15499.

Brock JA, McLachlan EM, Belmonte C (1998) Tetrodotoxin-resistant impulses in single nociceptor nerve terminals in guinea-pig cornea. J Physiol 512:211-217.

Brock JA, Pianova S, Belmonte C (2001) Differences between nerve terminal impulses of polymodal nociceptors and cold sensory receptors of the guinea-pig cornea. J Physiol 533:493-501.

Busserolles J, Tsantoulas C, Eschalier A, López García JA (2016) Potassium channels in neuropathic pain. Pain 157:S7-S14.

Carr RW, Pianova S, Fernandez J, Fallon JB, Belmonte C, Brock JA (2003) Effects of heating and cooling on nerve terminal impulses recorded from cold-sensitive receptors in the guinea-pig cornea. J Gen Physiol 121:427439.

Carrasquel-Ursulaez W, Moldenhauer H, Castillo JP, Latorre R, Alvarez O 
(2015) Biophysical analysis of thermosensitive TRP channels with a special focus on the cold receptor TRPM8. Temperature (Austin) $2: 188-200$.

Chao C, Golebiowski B, Stapleton F (2014) The role of corneal innervation in lasik-induced neuropathic dry eye. Ocul Surf 12:32-45.

De Felipe C, Belmonte C (1999) c-jun expression after axptomy of corneal trigeminal ganglion neurons is dependent on the site of injury. Eur J Neurosci 11:899-906.

Descoeur J, Pereira V, Pizzoccaro A, Francois A, Ling B, Maffre V, Couette B, Busserolles J, Courteix C, Noel J, Lazdunski M, Eschalier A, Authier N, Bourinet E (2011) Oxaliplatin-induced cold hypersensitivity is due to remodelling of ion channel expression in nociceptors. EMBO Mol Med $3: 266-278$.

Deuis JR, Zimmermann K, Romanovsky AA, Possani LD, Cabot PJ, Lewis RJ, Vetter I (2013) An animal model of oxaliplatin-induced cold allodynia reveals a crucial role for Nav1.6 in peripheral pain pathways. Pain 154:1749-1757.

Fang X, McMullan S, Lawson SN, Djouhri L (2005) Electrophysiological differences between nociceptive and non-nociceptive dorsal root ganglion neurones in the rat in vivo. J Physiol 565:927-943.

Galor A, Levitt RC, Felix ER, Martin ER, Sarantopoulos CD (2015) Neuropathic ocular pain: an important yet underevaluated feature of dry eye. Eye 29:301-312.

González A, Ugarte G, Piña R, Pertusa M, Madrid R (2015) TRP channels in cold transduction. In: TRP channels in sensory transduction (Madrid R, Bacigalupo J, eds), pp 185-207. Cham: Springer International Publishing.

González A, Herrera G, Ugarte G, Restrepo C, Piña R, Pertusa M, Orio P, Madrid R (2017a) $I_{\mathrm{KD}}$ current in cold transduction and damagetriggered cold hypersensitivity. Adv Exp Med Biol 1015:265-277.

González A, Ugarte G, Restrepo C, Herrera G, Piña R, Gómez-Sánchez JA, Pertusa M, Orio P, Madrid R (2017b) Role of the excitability brake potassium current $I_{\mathrm{KD}}$ in cold allodynia induced by chronic peripheral nerve injury. J Neurosci 37:3109-3126.

González-González O, Bech F, Gallar J, Merayo-Lloves J, Belmonte C (2017) Functional properties of sensory nerve terminals of the mouse cornea. Invest Ophthalmol Vis Sci 58:404-415.

Hensel H, Zotterman Y (1951) The response of the cold receptors to constant cooling. Acta Physiol Scand 22:96-105.

Hines M, Davison AP, Muller E (2009) NEURON and Python. Front Neuroinform 3:1.

Hines ML, Carnevale NT (1997) The NEURON simulation environment. Neural Comput 9:1179-1209.

Hirata H, Meng ID (2010) Cold-sensitive corneal afferents respond to a variety of ocular stimuli central to tear production: implications for dry eye disease. Invest Ophthalmol Vis Sci 51:3969-3976.

Hirata H, Fried N, Oshinsky ML (2012) Quantitative characterization reveals three types of dry-sensitive corneal afferents: pattern of discharge, receptive field, and thermal and chemical sensitivity. J Neurophysiol 108: 2481-2493.

Iggo A (1969) Cutaneous thermoreceptors in primates and sub-primates. J Physiol 200:403-430.

Kovács I, Dienes L, Perényi K, Quirce S, Luna C, Mizerska K, Acosta MC, Belmonte C, Gallar J (2016a) Lacosamide diminishes dryness-induced hyperexcitability of corneal cold sensitive nerve terminals. Eur J Pharmacol 787:2-8

Kovács I, Luna C, Quirce S, Mizerska K, Callejo G, Riestra A, FernándezSánchez L, Meseguer VM, Cuenca N, Merayo-Lloves J, Acosta MC, Gasull X, Belmonte C, Gallar J (2016b) Abnormal activity of corneal cold thermoreceptors underlies the unpleasant sensations in dry eye disease. Pain 157:399-417.

Leffler A, Cummins TR, Dib-Hajj SD, Hormuzdiar WN, Black JA, Waxman SG (2002) GDNF and NGF reverse changes in repriming of TTXsensitive $\mathrm{Na}+$ currents following axotomy of dorsal root ganglion neurons. J Neurophysiol 88:650-658.

Linte RM, Ciobanu C, Reid G, Babes A (2007) Desensitization of cold- and menthol-sensitive rat dorsal root ganglion neurones by inflammatory mediators. Exp Brain Res 178:89-98.

Litwak S, Zadok D, Garcia-de Quevedo V, Robledo N, Chayet AS (2002) Laser-assisted subepithelial keratectomy versus photorefractive keratectomy for the correction of myopia: a prospective comparative study. J Cataract Refract Surg 28:1330-1333.

Lolignier S, Gkika D, Andersson D, Leipold E, Vetter I, Viana F, Noël J,
Busserolles J (2016) New Insight in Cold Pain: Role of Ion Channels, Modulation, and Clinical Perspectives. J Neurosci 36:11435-11439.

Madrid R, Pertusa M (2014) Intimacies and physiological role of the polymodal cold-sensitive ion channel TRPM8. Curr Top Membr 74: 293-324.

Madrid R, Donovan-Rodríguez T, Meseguer V, Acosta MC, Belmonte C, Viana F (2006) Contribution of TRPM8 channels to cold transduction in primary sensory neurons and peripheral nerve terminals. J Neurosci 26:12512-12525.

Madrid R, de la Peña E, Donovan-Rodriguez T, Belmonte C, Viana F (2009) Variable threshold of trigeminal cold-thermosensitive neurons is determined by a balance between TRPM8 and Kv1 potassium channels. J Neurosci 29:3120-3131.

Mälkiä A, Madrid R, Meseguer V, de La Peña E, Valero M, Belmonte C, Viana F (2007) Bidirectional shifts of TRPM8 channel gating by temperature and chemical agents modulate the cold sensitivity of mammalian thermoreceptors. J Physiol 581:155-174.

Marfurt CF, Cox J, Deek S, Dvorscak L (2010) Anatomy of the human corneal innervation. Exp Eye Res 90:478-492.

McKemy DD, Neuhausser WM, Julius D (2002) Identification of a cold receptor reveals a general role for TRP channels in thermosensation. Nature 416:52-58.

Mergler S, Valtink M, Takayoshi S, Okada Y, Miyajima M, Saika S, Reinach PS (2014) Temperature-sensitive transient receptor potential channels in corneal tissue layers and cells. Ophthalmic Res 52:151-159.

Morenilla-Palao C, Luis E, Fernández-Peña C, Quintero E, Weaver JL, Bayliss DA, Viana F (2014) Ion channel profile of TRPM8 cold receptors reveals a role of TASK-3 potassium channels in thermosensation. Cell Rep 8:1571-1582.

Nettune GR, Pflugfelder SC (2010) Post-LASIK tear dysfunction and dysesthesia. Ocul Surf 8:135-145.

Olivares E, Orio P (2015) Mathematical modeling of TRPM8 and the cold thermoreceptors. In: TRP channels in sensory transduction (Madrid R, Bacigalupo J, eds), pp 209-223. Cham: Springer International Publishing.

Olivares E, Salgado S, Maidana JP, Herrera G, Campos M, Madrid R, Orio P (2015) TRPM8-dependent dynamic response in a mathematical model of cold thermoreceptor. PLoS One 10:e0139314.

Orio P, Madrid R, de La Peña E, Parra A, Meseguer V, Bayliss DA, Belmonte C, Viana F (2009) Characteristics and physiological role of hyperpolarization activated currents in mouse cold thermoreceptors. J Physiol 587: 1961-1976.

Orio P, Parra A, Madrid R, González O, Belmonte C, Viana F (2012) Role of Ih in the firing pattern of mammalian cold thermoreceptor endings. J Neurophysiol 108:3009-3023.

Parra A, Madrid R, Echevarria D, del Olmo S, Morenilla-Palao C, Acosta MC, Gallar J, Dhaka A, Viana F, Belmonte C (2010) Ocular surface wetness is regulated by TRPM8-dependent cold thermoreceptors of the cornea. Nat Med 16:1396-1399.

Parra A, Gonzalez-Gonzalez O, Gallar J, Belmonte C (2014) Tear fluid hyperosmolality increases nerve impulse activity of cold thermoreceptor endings of the cornea. Pain 155:1481-1491.

Peier AM, Moqrich A, Hergarden AC, Reeve AJ, Andersson DA, Story GM, Earley TJ, Dragoni I, McIntyre P, Bevan S, Patapoutian A (2002) A TRP channel that senses cold stimuli and menthol. Cell 108:705-715.

Pereira V, Busserolles J, Christin M, Devilliers M, Poupon L, Legha W, Alloui A, Aissouni Y, Bourinet E, Lesage F, Eschalier A, Lazdunski M, Noël J (2014) Role of the TREK2 potassium channel in cold and warm thermosensation and in pain perception. Pain 155:2534-2544.

Pertusa M, Madrid R (2017) The $I_{\mathrm{KD}}$ current in cold detection and pathological cold pain. Temperature (Austin) 4:346-349.

Pflugfelder SC, Stern M, Zhang S, Shojaei A (2017) LFA-1/ICAM-1 interaction as a therapeutic target in dry eye disease. J Ocul Pharmacol Ther 33:5-12.

Quallo T, Vastani N, Horridge E, Gentry C, Parra A, Moss S, Viana F, Belmonte C, Andersson DA, Bevan S (2015) TRPM8 is a neuronal osmosensor that regulates eye blinking in mice. Nat Commun 6:7150.

Raivich G, Makwana M (2007) The making of successful axonal regeneration: genes, molecules and signal transduction pathways. Brain Res Rev 53:287-311

Reid G, Babes A, Pluteanu F (2002) A cold- and menthol-activated current in rat dorsal root ganglion neurones: properties and role in cold transduction. J Physiol 545:595-614. 
Rosenthal P, Borsook D (2012) The corneal pain system. Part I: the missing piece of the dry eye puzzle. Ocul Surf 10:2-14.

Stapleton F, Marfurt C, Golebiowski B, Rosenblatt M, Bereiter D, Begley C, Dartt D, Gallar J, Belmonte C, Hamrah P, Willcox M (2013) The TFOS International Workshop on Contact Lens Discomfort: Report of the subcommittee on neurobiology. Invest Ophthalmol Vis Sci 54: TFOS71-97.

Storm JF (1988) Temporal integration by a slowly inactivating K+ current in hippocampal neurons. Nature 336:379-381.

Thut PD, Wrigley D, Gold MS (2003) Cold transduction in rat trigeminal ganglia neurons in vitro. Neuroscience 119:1071-1083.

Viana F, de la Peña E, Belmonte C (2002) Specificity of cold thermotransduction is determined by differential ionic channel expression. Nat Neurosci 5:254-260.
Voets T, Droogmans G, Wissenbach U, Janssens A, Flockerzi V, Nilius B (2004) The principle of temperature-dependent gating in cold- and heatsensitive TRP channels. Nature 430:748-754.

Vriens J, Nilius B, Voets T (2014) Peripheral thermosensation in mammals. Nat Rev Neurosci 15:573-589.

Wang D, Chen G, Tang L, Li Q (2014) Comparison of postoperative pain following laser-assisted subepithelial keratectomy and transepithelial photorefractive keratectomy: a prospective, random paired bilateral eye study. Eye Sci 29:155-159.

Waxman SG, Zamponi GW (2014) Regulating excitability of peripheral afferents: emerging ion channel targets. Nat Neurosci 17:153-163.

Zhang X, Mak S, Li L, Parra A, Denlinger B, Belmonte C, McNaughton PA (2012) Direct inhibition of the cold-activated TRPM8 ion channel by G $\alpha$ q. Nat Cell Biol 14:851-858. 